\title{
Albedo and heat transport in 3-D model simulations of the early Archean climate
}

\author{
H. Kienert, G. Feulner, and V. Petoukhov \\ Potsdam Institute for Climate Impact Research, Telegrafenberg A62, 14473 Potsdam, Germany \\ Correspondence to: H. Kienert (kienert@pik-potsdam.de) \\ Received: 21 December 2012 - Published in Clim. Past Discuss.: 24 January 2013 \\ Revised: 5 June 2013 - Accepted: 24 June 2013 - Published: 7 August 2013
}

\begin{abstract}
At the beginning of the Archean eon (ca. 3.8 billion years ago), the Earth's climate state was significantly different from today due to the lower solar luminosity, smaller continental fraction, higher rotation rate and, presumably, significantly larger greenhouse gas concentrations. All these aspects play a role in solutions to the "faint young Sun paradox" which must explain why the ocean surface was not fully frozen at that time. Here, we present 3-D model simulations of climate states that are consistent with early Archean boundary conditions and have different $\mathrm{CO}_{2}$ concentrations, aiming at an understanding of the fundamental characteristics of the early Archean climate system. In order to do so, we have appropriately modified an intermediate complexity climate model that couples a statistical-dynamical atmosphere model (involving parameterizations of the dynamics) to an ocean general circulation model and a thermodynamic-dynamic sea-ice model. We focus on three states: one of them is ice-free, one has the same mean surface air temperature of $288 \mathrm{~K}$ as today's Earth and the third one is the coldest stable state in which there is still an area with liquid surface water (i.e. the critical state at the transition to a "snowball Earth"). We find a reduction in meridional heat transport compared to today, which leads to a steeper latitudinal temperature profile and has atmospheric as well as oceanic contributions. Ocean surface velocities are largely zonal, and the strength of the atmospheric meridional circulation is significantly reduced in all three states. These aspects contribute to the observed relation between global mean temperature and albedo, which we suggest as a parameterization of the ice-albedo feedback for 1-D model simulations of the early Archean and thus the faint young Sun problem.
\end{abstract}

\section{Introduction}

During the Archean eon ( 3.8 billion years to 2.5 billion years ago), the Sun's luminosity increased from about $75 \%$ to about $82 \%$ of its present-day value (Bahcall et al., 2001). In this light, indicators of liquid surface water (Lowe, 1980; Walker, 1982) raise the question regarding which mechanisms counteracted this lower luminosity, a problem that was first explicitly phrased by Sagan and Mullen (1972) and is known as the "faint young Sun problem" (Feulner, 2012).

Most solutions that have been suggested involve larger greenhouse gas concentrations. Their warming impacts on global temperature and thus glaciation have mainly been studied with 1-D radiative-convective models (e.g. Kasting et al., 1984; Kiehl and Dickinson, 1987; von Paris et al., 2008). However, these models do not represent any 3-D effects as meridional heat transport or albedo changes due to continents, sea ice or clouds (Kasting, 2010). A few early studies of the Archean climate applied 3-D models (Jenkins, 1993a, 1996). However, while these simulations are based on an atmospheric general circulation model (GCM), they do not involve full ocean or sea-ice modules. Furthermore, Jenkins (1993a) has reduced the solar constant compared to today by 10 and $15 \%$ which does not correspond to the actual Archean values. Due to a limited number of simulations, no critical $\mathrm{CO}_{2}$ partial pressure required to prevent the Earth's surface from fully freezing was explicitly identified in these studies.

This is the second in a series of papers investigating the Archean climate with 3-D model simulations using a fully coupled ocean-atmosphere-sea ice model. The ocean component of the model is a GCM, but the atmosphere is simpler than a GCM and involves several parameterizations. 
The sea-ice component takes into account thermodynamics as well as dynamics. In the first paper, we have shown that the critical $\mathrm{CO}_{2}$ partial pressure required to prevent the Earth from freezing amounts to 0.4 bar (Kienert et al., 2012). Because of the 3-D effects mentioned above, this is significantly higher than previous results with radiative-convective models (Kasting et al., 1984; Kiehl and Dickinson, 1987; von Paris et al., 2008). A partial pressure of 0.6 bar is sufficient to keep the Earth at a temperature close to the present-day mean SAT of $288 \mathrm{~K}$. The difference between the $\mathrm{CO}_{2}$ partial pressures corresponding to the critical state and the state with $288 \mathrm{~K}$ is very small (factor of 1.5 ), which is mainly caused by the ice albedo feedback that is neglected in the 1-D model studies. Here, we use the same model with identical parameters to study key characteristics of the early Archean climate, in particular albedo and heat transport.

On the most fundamental level, the Earth's global energy balance is set by solar irradiance and planetary albedo. Contributions to albedo variations especially arise from clouds and changes in surface type. Due to the high reflectivity of snow and ice, the sea-ice albedo feedback plays an important role in case of significant glaciation, as was already shown four decades ago by Budyko (1969). There are times in Earth's history, for which strong indications for extensive sea-ice cover or even for the occurrence of a fully frozen ocean surface in a so-called "snowball state" (Kirschvink, 1992) have been found. In this context, the question of critical greenhouse gas amounts with respect to global glaciation has already been posed and studied for the Marinoan Earth (about $650 \mathrm{Myr}$ ago). In contrast to research on the Archean climate, several palaeostudies on that time period even use full atmosphere-ocean GCMs (e.g. Voigt and Marotzke, 2010; Voigt et al., 2011) and thus also include the albedo effect of changing sea-ice cover.

Meridional heat transport from low to high latitudes is effecting the latitudinal temperature profile and is thus coupled to the formation of sea ice. Therefore, the specific horizontal redistribution of heat in the climate system indirectly affects the global energy balance. In order to characterize this heat transport and the underlying atmospheric and oceanic dynamics, not only a 3-D model with appropriate external boundary conditions (such as solar irradiance and differences in the Earth's rotation rate) is needed, but a realistic topography must be implemented. In the early Archean, the emerged surface area was much smaller than today because of less continental crust as well as due to continents having been submerged under different hypsometry (Flament, 2009) so that some similarities in the dynamics of the climate system with aquaplanet (an idealised planet fully covered by oceans) states might be expected. Many atmospheric modelling studies exist which assume oceanic boundary conditions without continents (with a reduced solar constant, e.g. Jenkins, 1993b). But the number of aquaplanet (or near-aquaplanet) studies taking into account the coupled ocean-atmosphere system and thus the full impact of the vanishing continental fraction is very limited (Smith et al., 2006; Marshall et al., 2007; Enderton and Marshall, 2009; Ferreira et al., 2010), and none of them employs Archean boundary conditions.

Here, we show how the early Archean must have differed from the present-day climate, especially with respect to its energy balance, which determines the critical greenhouse gas concentrations. Therefore, we put a special focus on albedo and heat transport when analysing the simulated climate states. We will first, in Sect. 2, describe the model as well as the modifications that were implemented in order to allow for the application of early Archean boundary conditions (see Sect. 3). We will continue in Sect. 4 with describing the key characteristics of the early Archean climate states with a special focus on albedo and heat transport which are essential for setting up a relation between greenhouse gases and global mean temperature. In Sect. 5, we investigate the robustness of our results with respect to uncertainties in model parameters and boundary conditions. Then, we use a larger set of simulations in Sect. 6 in order to suggest a parameterization of the ice-albedo effect in the early Archean for 1-D radiative-convective models. Open issues and suggestions for future work are discussed in Sects. 7 and 8, respectively, before our results are summarized in Sect. 9 .

\section{Model description}

\subsection{Original model and main settings}

The simulations of the Archean climate are performed with a modified version of CLIMBER-3 $\alpha$ (Montoya et al., 2005), which is an earth system model of intermediate complexity (EMIC, Claussen et al., 2002). CLIMBER-3 $\alpha$ basically consists of an improved version of the ocean general circulation model MOM3 (Pacanowski and Griffies, 1999; Hofmann and Morales Maqueda, 2006), the statistical-dynamical atmosphere model POTSDAM-2 (Petoukhov et al., 2000) and the thermodynamic-dynamic sea-ice model ISIS (Fichefet and Morales Maqueda, 1997). Under pre-industrial conditions, the model reacts to a doubling of the atmospheric $\mathrm{CO}_{2}$ concentration with a rise in surface air temperature by $3.2 \mathrm{~K}$. For simulations of the last millennium and future climate, the model is well established and has contributed to different model intercomparisons (e.g. Gregory et al., 2005; Stouffer et al., 2006; Jansen et al., 2007; Plattner et al., 2008; Eby et al., 2013). In total, the model simulates approximately 200 model-years per day of integration on a single CPU, which makes it possible to perform a large number of ensemble simulations until they approach equilibrium after $5000 \mathrm{yr}$ in this study. This is particularly important for investigations of deep-time palaeoclimate problems because uncertainties in boundary conditions can be systematically explored.

The ocean and sea-ice components have a horizontal resolution of $3.75^{\circ}$. The ocean module has 20 vertical levels with the bathymetry that we use for the simulation of 
the Archean ocean, and it applies a non-linear explicit free surface scheme. Vertical mixing is parameterized via the KPP scheme in the boundary layer (Large et al., 1994). As background values, we use $10 \mathrm{~cm}^{2} \mathrm{~s}^{-1}$ for viscosity and a Bryan-Lewis profile (Bryan and Lewis, 1979) for diffusivity. The parameters for the latter are modified so that the vertical background diffusivity takes values between the same (present-day CLIMBER-3 $\alpha$ ) limits of $0.3 \mathrm{~cm}^{2} \mathrm{~s}^{-1}$ at the surface and $1.3 \mathrm{~cm}^{2} \mathrm{~s}^{-1}$ at the maximum ocean depth also for our modified topography.

The viscosity for Laplacian horizontal mixing of momentum is constant in time and depth and has a latitude-dependent cosine-profile with a maximum value of $3.2 \times 10^{9} \mathrm{~cm}^{2} \mathrm{~s}^{-1}$. Isoneutral tracer mixing is achieved via a small-angle approximated (Gent and McWilliams, 1990) Redi diffusion tensor (Redi, 1982) and GentMcWilliams parameterization of eddy stirring (Gent and McWilliams, 1990). The respective diffusivities are constant and have values of $2.0 \times 10^{7} \mathrm{~cm}^{2} \mathrm{~s}^{-1}$ for Redi diffusion and $0.25 \times 10^{7} \mathrm{~cm}^{2} \mathrm{~s}^{-1}$ for the Gent-McWilliams parameterization. These values are the same as in the standard present-day version of the model.

The atmosphere model has a resolution of $7.5^{\circ} \times 22.5^{\circ}$ and assumes a linear decrease of temperature in the troposphere with a lapse rate calculated by the model as well as an isothermal stratosphere above. Instead of explicitly resolving synoptic scale processes, their statistical behaviour is modelled. In contrast to the standard version of CLIMBER-3 $\alpha$, we do not use the wind-anomaly model here, but keep winds fully free to evolve.

Note that the land surface is free of vegetation in all our simulations of the early Archean. The following clear-sky albedo values are used: 0.17 for bare land (Tsvetsinskaya et al., 2002), as well as 0.53 and 0.72 for thick sea ice under melting and freezing conditions, respectively (Shine and Henderson-Sellers, 1985). Sea ice covered by thick snow has albedo values of 0.65 and 0.8 , correspondingly (Shine and Henderson-Sellers, 1985).

\subsection{Cloud scheme}

Clouds are of critical importance for the planetary energy balance and thus merit special attention. The cloud scheme of our model distinguishes between stratus and cumulus cloud fractions which are calculated from relative humidity, specific humidity and an effective vertical velocity. In general, there is a significant spread even in the results of state-of-the-art models when simulating cloud cover for today's climate, and differences to satellite observations are quite large (Cesana and Chepfer, 2012). In Fig. 1, the total pre-industrial and present-day cloud fractions simulated with our model are compared to results from other models as well as observations. We find that our results are within the range of those from climate models which took part in the CMIP5 intercomparison project (dashed lines, data from
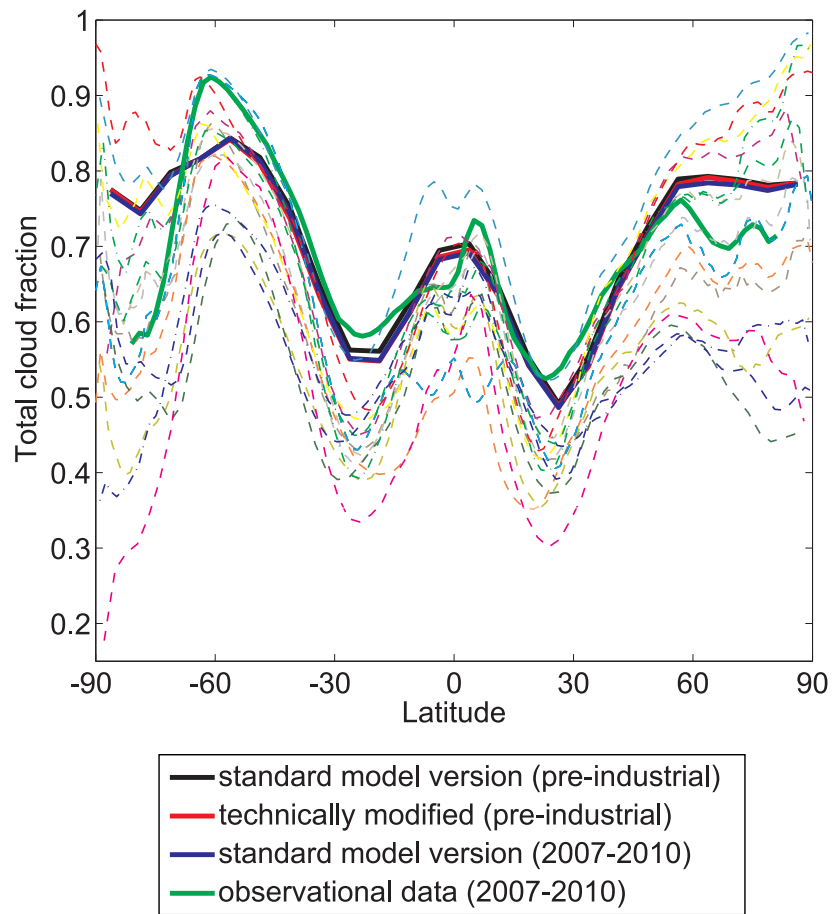

Fig. 1. Annual and zonal mean total cloud fraction. The solid lines show results from our model for the present-day (blue) and preindustrial climate (standard model version in black, technically modified version as described in Sect. 2.4 given in red) as well as observational data (green, CALIPSO-GOCCP v2.1, Chepfer et al., 2010). For comparison, the dashed lines represent the results from simulations of the pre-industrial climate with different CMIP5 models (Taylor et al., 2012).

the pre-industrial control simulations, Taylor et al., 2012). In low- and mid-latitudes, the annual mean cloudiness simulated with our model is closer to observations (CALIPSOGOCCP data v2.1, Chepfer et al., 2010) than most of the other models, but there is a tendency to overestimate the cloud fraction in the cold polar regions above ice.

\subsection{Model modifications}

In order to simulate the climate of the Archean, the boundary conditions which differ from today's world have to be taken into account. This includes a different bathymetry and land fraction as well as a higher rotation rate of the Earth, larger greenhouse-gas (GHG) partial-pressures (in terms of $\mathrm{CO}_{2}$ equivalents) and a lower solar constant. The implementation of these boundary conditions demands some prior modifications of our model.

\subsubsection{Long-wave radiative transfer}

The long-wave radiative (LWR) transfer code of CLIMBER$3 \alpha$ is based on a two-stream approximation using integrated transmission functions (ITFs) for water vapour and $\mathrm{CO}_{2}$ 
(Petoukhov et al., 2003). Recent results suggest that the most commonly used parameterization in radiative transfer codes overestimates warming for $\mathrm{CO}_{2}$-rich atmospheres (Wordsworth et al., 2010) due to the treatment of continuum absorption. Therefore, we have tuned the model code to approximate the results of the MTCKD parameterization (Halevy et al., 2009) in addition to implementing a dependency on total pressure motivated by the large range of $\mathrm{CO}_{2}$ partial pressures used in our set of simulations. A single parameter $(a)$ was varied in our model while surface temperature and lapse rate were fixed to the values given in Halevy et al. (2009), and the outgoing long-wave radiation (OLR) in our model was compared with the results from three parameterizations provided by Halevy et al. (2009): MTCKD (cf. Clough et al., 2005), CA (cf. Meadows and Crisp, 1996) and GBKM (cf. Segura et al., 2007). This comparison is shown in Fig. 2 with respect to a range of $\mathrm{CO}_{2}$ partial pressures in a dry atmosphere and a range of relative humidity in an atmosphere with a $\mathrm{CO}_{2}$ partial pressure of 0.5 bar. It leads to the choice of $a=0.008$, with the mean deviations from the MTCKD parameterization being about $-1.6 \mathrm{~W} \mathrm{~m}^{-2}$ for the dry atmospheres and about $3.1 \mathrm{~W} \mathrm{~m}^{-2}$ for the moist atmospheres with $p \mathrm{CO}_{2}=0.5$ bar.

Although the MTCKD parameterization can arguably be considered the best representation of radiative transfer in $\mathrm{CO}_{2}$-rich atmospheres, all three parameterizations are used in the literature and fit the observations for low- $\mathrm{CO}_{2}$ atmospheres. Therefore, we performed additional sets of simulations of the early Archean climate in which our LWR parameter takes the values $a=0.006$ and $a=0.010$ in order to explore this uncertainty, and the main results from this exercise are presented in Sect. 5.2.

\subsubsection{Parameterization of atmospheric meridional cell strength}

The dynamics of the atmosphere are important for heat transport as well as for driving the ocean circulation. In the standard version of the model, the atmospheric meridional circulation consists of Hadley, Ferrel and Polar cell in each hemisphere. When simulating the present-day climate, the cell boundary positions are in a first step fixed to latitudes of 0,30 and $60^{\circ}$, while the actual position at each point of time is adjusted in a second step according to the position of the thermal equator (Petoukhov et al., 2000). The strength of each cell is parameterized in terms of the mean temperature $T_{i}$ within the cell and the temperature contrast $\Delta T_{i}$ between its boundaries $\left(\phi_{i-1}\right.$ and $\left.\phi_{i}\right)$ :

$\left|v_{1}(\phi)\right|=C_{i} \times 3.5 \times 10^{-2} \times\left(\frac{T_{i}}{T_{*}}\right)^{3} \times\left|\Delta T_{i}\right| \times \sin \left(\pi \frac{\phi-\phi_{i}}{\phi_{i-1}-\phi_{i}}\right)$

where $T_{*}=273 \mathrm{~K}$, and $v_{1}(\phi)$ is the meridional velocity in the planetary boundary layer (in $\mathrm{m} \mathrm{s}^{-1}$ ) and thus a measure for the cell strength (Petoukhov et al., 2000). The six coefficients
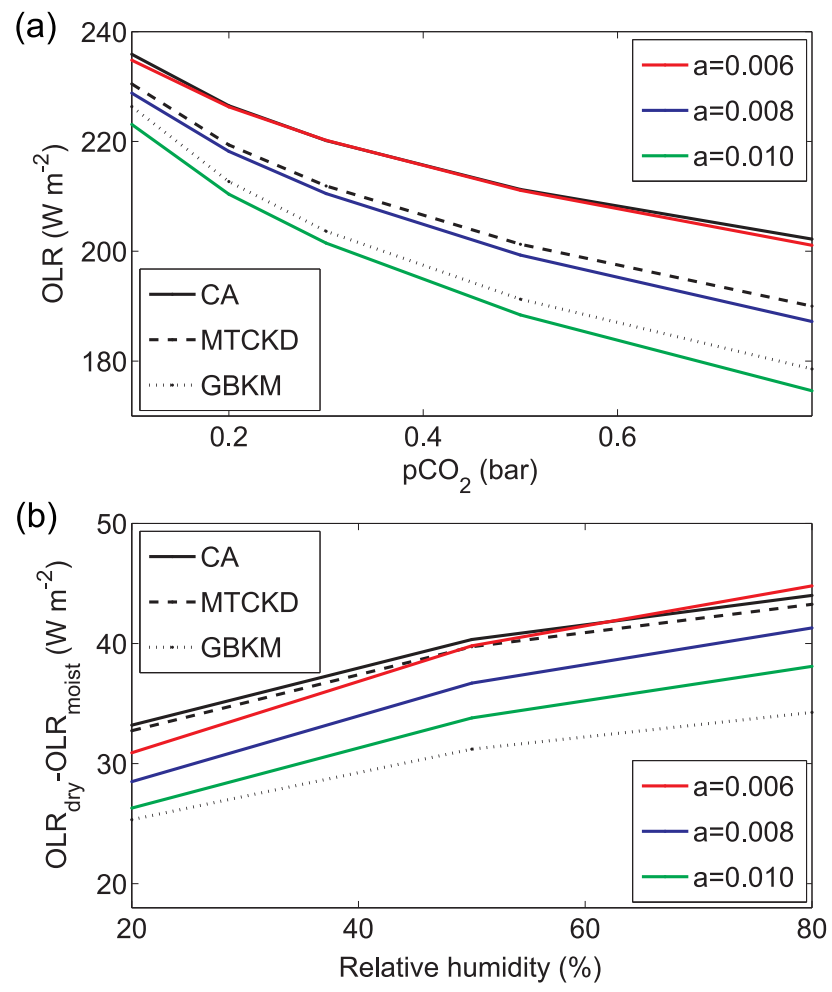

Fig. 2. Tuning of the long-wave radiation scheme to approximate the MTCKD parameterization for high partial pressures of $\mathrm{CO}_{2}$. Black lines show the outgoing long-wave radiation under fixed boundary conditions for three different parameterizations as in Halevy et al. (2009). Coloured lines show the outgoing long-wave radiation under the same boundary conditions as in our model simulations for different values of the parameter $a$. (a) displays the dependency on $\mathrm{CO}_{2}$ partial pressure in a dry atmosphere, while panel (b) shows the effect of water vapour on an atmosphere with $p \mathrm{CO}_{2}=0.5 \mathrm{bar}$ in terms of OLR. Note the different scales of the two panels.

$C_{i}$ are originally determined empirically for the present-day climate.

In today's climate, the $C_{i}$-factors are influenced by the present-day continent structure and orography because they basically parameterize the loss of kinetic energy due to friction and are therefore not hemispherically symmetric. Since the area of emerged surface in the early Archean was very small, we have adjusted these parameters to aquaplanet conditions. The temperature and velocity fields from aquaplanet simulations with a more complex atmospheric model (Marshall et al., 2007) are used to calculate values for the $C_{i^{-}}$ factors that are - after symmetrisation - appropriate for an (almost) continent-free world (Table 1). Their symmetry as well as their similarity with the present-day values give confidence in the model parameterization. Nevertheless, it would be desirable to compare our results with an atmosphereocean GCM in order to confirm that this parameterization 
Table 1. Empirical $C_{i}$-factors for the parameterization of the atmospheric meridional cell strength in terms of the temperature field. Present-day values are from the standard version of CLIMBER-3 $\alpha$, and aquaplanet values are based on a comparison with modelling results by Marshall et al. (2007). For the Archean, we have chosen the factors in the last column which are close to the aquaplanet values, but symmetrical about the equator.

\begin{tabular}{lccc}
\hline & Present-day & Aquaplanet & Archean \\
\hline Northern Polar cell & 0.1 & 0.22 & 0.21 \\
Northern Ferrel cell & 0.4 & 0.36 & 0.36 \\
Northern Hadley cell & 4.5 & 3.36 & 3.40 \\
Southern Hadley cell & 3.0 & 3.45 & 3.40 \\
Southern Ferrel cell & 0.8 & 0.36 & 0.36 \\
Southern Polar cell & 0.2 & 0.21 & 0.21 \\
\hline
\end{tabular}

holds for a large range of $\mathrm{CO}_{2}$ partial pressures and therefore temperatures.

\subsubsection{Rotation rate of the Earth}

The rotation rate of the Earth was higher by a factor of 1.6 in the early Archean compared to today (Zahnle and Walker, 1987) and since then, the day length has become longer due to tidal friction. While the Coriolis force explicitly enters the fundamental equations in the ocean and sea-ice module as well as in parts of the atmospheric module, it further affects the positions of the atmospheric meridional cell boundaries, potentially the number of cells, as well as the lapse rate which are the most important non-fundamental quantities in the model. Thus, these two parameterizations had to be modified so that rotation rates higher than today's can be applied.

Williams (1988) presents results of a study with an atmospheric general circulation model that explicitly calculates the atmospheric cell boundaries for a wide range of parameter changes, including a doubling of the Earth's rotation rate. From his results for a moist and for a dry atmosphere (for single and double present-day rotation rate), one may estimate approximate cell boundaries of 20 and $50^{\circ}$ for a rotation rate increased by a factor of 1.6.

The fact that the Hadley cells become narrower with increasing rotation rate is also consistent with the results by Jenkins et al. (1993) and can be understood from conceptual models of atmospheric circulation. In the Held and Hou (1980) model, the extent of the Hadley cell (and its dependence on rotation rate) are obtained by requiring the cell to be energetically closed and a smooth transition of temperature at the poleward boundary to radiative equilibrium conditions; alternatively, the Hadley cell width can be regarded as limited by the onset of baroclinic instability at higher latitudes (for reviews, see Schneider, 2006; Showman et al., 2011). In either case an increase in rotation rate leads to narrower Hadley cells.
Held and Hou (1980) find the following relation for the Hadley cell boundary $\theta$ :

$$
\theta \leq \arctan \left(\left[(1+2 R)^{1 / 2}-1\right]^{1 / 2}\right), \quad R=\frac{g H \Delta T}{\left(\Omega_{\mathrm{E}} a\right)^{2}},
$$

where $g$ is the gravitational acceleration, $H$ the atmosphere height, $\Delta T$ the fractional change in equator-to-pole potential-temperature difference, $\Omega_{\mathrm{E}}$ the rotation rate of the Earth, and $a$ the Earth's radius. It turns out that the change in $\Omega_{E}$ has the most important effect on $R$, and it is the only one taken into account when we fix the annual mean cell boundaries. Equation (2) gives a value of $\theta=30^{\circ}$ for present-day input parameters (Navarra and Boccaletti, 2002), and $\Omega=1.6$ leads to $\theta \leq 20.6^{\circ}$. In order to keep the mean cell boundaries at the grid cell boundaries of the model for the early Archean, we have chosen values of 22.5 and $52.5^{\circ}$ for $\Omega=1.6$ which are multiples of our model resolution of $7.5^{\circ}$ in latitude. For different rotation rates, the annual-mean atmospheric cell boundaries are determined by linear interpolation and extrapolation based on their present-day values and these values for $\Omega=1.6$.

The lapse rate in CLIMBER-3 $\alpha$ is dependent on the local temperature $T_{\mathrm{a}}$, specific humidity $q_{\mathrm{s}}$ and cumulus cloud fraction $n_{\mathrm{c}}$ (Petoukhov et al., 2000):

$\Gamma=\Gamma_{0}+\Gamma_{1} \times\left(T_{\mathrm{a}}-273.16 \mathrm{~K}\right) \times\left(1-a_{q} \times q_{\mathrm{s}}^{2}\right)-\Gamma_{2} \times n_{\mathrm{c}}$,

where $\Gamma_{0}, \Gamma_{1}, \Gamma_{2}$ and $a_{q}$ are model parameters. The statistical effect of extratropical eddies is implicitly taken into account in this parameterization (following Monin-ObukhovKazanski similarity theory; see, e.g. Zilitinkevich, 1969). While the coefficients $\Gamma_{i}$ are fixed in the standard model version, they are more generally dependent on the Earth's rotation rate. In order to allow for an impact of higher rotation rates on the lapse rate, we have implemented an explicit calculation of the $\Gamma_{i}$ which involves a proportionality to $k_{0}(\Omega)^{-1}$ (Zilitinkevich, 1970), with $k_{0}(\Omega)$ given as follows:

$k_{0}=1+\left(\frac{\Omega}{\Omega_{\mathrm{PD}}}\right)^{0.25} \times\left(c_{\mathrm{vd}} / c_{\mathrm{pd}}\right)$,

where $\Omega_{\mathrm{PD}}$ is the present-day rotation rate, and $c_{\mathrm{vd}}$ and $c_{\mathrm{pd}}$ are the constant volume and constant pressure heat capacities of the present-day atmosphere. For a rotation rate of $\Omega=1.6$, the values of the parameters are $\Gamma_{0}=5.1 \times 10^{-3}$, $\Gamma_{1}=6.1 \times 10^{-5}, \Gamma_{2}=9.0 \times 10^{-4}$ and $a_{q}=1171$.

Temperature inversions over sea-ice are taken into account in Eq. (3), but a cap of $3 \mathrm{~K} \mathrm{~km}^{-1}$ is applied. Note that modelsimulations with CLIMBER-3 $\alpha$ that include the unmodified lapse-rate parameterization have been validated for the present-day climate (and its seasonal cycle) and thus for a significant range of surface air temperatures from those over Antarctica to those in the equatorial region. 


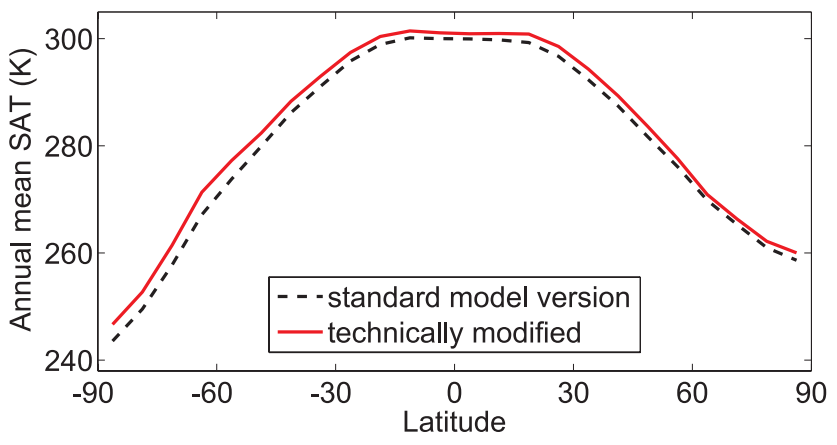

Fig. 3. Pre-industrial SAT profile for standard model equilibrium and the version with implementation of technical changes required for applying Archean boundary conditions later on.

\subsection{Overall impact of technical modifications}

Some of the above code modifications, which are a prerequisite for the implementation of Archean boundary conditions, also have an impact on the simulated present-day state. Firstly, the coefficients $\Gamma_{i}$ in the lapse rate calculation are now explicitly calculated instead of being fixed, so that slightly different values arise also for present-day conditions. Secondly, the parameter $a$ in the long-wave radiation scheme has been changed. We further had to extend the range of latitudes in which filtering of fast modes is applied for reasons of numeric stability. Additionally, more appropriate sea-ice albedo values have been chosen. Finally, the wind stress has been set free.

As the model is validated for the pre-industrial climate (present-day continents, vegetation and ice sheets, $\left.S_{0}=1365 \mathrm{~W} \mathrm{~m}^{-2}, p \mathrm{CO}_{2}=280 \mathrm{ppm}\right)$, it is desirable that these changes only have a minor effect on the overall climate state. Figure 3 shows the impact of these technical changes on the pre-industrial latitudinal SAT profile. Global mean overall warming due to these changes is $1.8 \mathrm{~K}$ which is smaller than the differences between present-day climate states simulated with 12 EMICs in a recent intercomparison project (Eby et al., 2013).

\section{Boundary conditions and overview of simulations}

\subsection{Topography}

It has long been generally accepted that $70 \%$ or more of today's continental crust had already been separated from the mantle by the end of the Archean (Kröner, 1985). However, there is a lot of controversy and uncertainty with respect to the question of when and how fast continental crust grew. Isotopic data (e.g. Belousova et al., 2010; Dhuime et al., 2012) and theoretical arguments on the growth and subduction processes (Flament, 2009) give some indications. Several models based on the age distribution of preserved minerals or sediments (Hurley and Rand, 1969; Taylor and

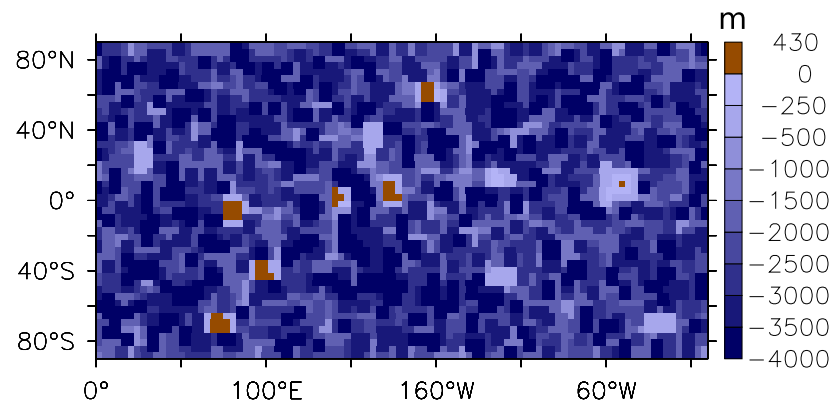

Fig. 4. Early Archean topography used in this study. This specific ocean depth field is created randomly but respects an area-per-depth distribution based on geological modelling and exhibits an emerged surface area of $1 \%$.

McLennan, 1985) suggest only a few percent of today's continental volume for the early Archean. Note however, that a study by Campbell (2003) indicates that already more than $40 \%$ of today's crust were formed $3.8 \mathrm{Ga}$ ago. The smaller fraction of emerged land has had an impact on the surface albedo of the Earth and potentially on evaporation together with cloud formation; the different bathymetry in general influences meridional heat transport with consequences for the sea-ice fraction and thus the total energy balance.

Due to the lack of knowledge regarding land distribution, there is neither a specific topography field nor a known distribution of emerged continents that could be used for model simulations. We thus use a set of fields whose details are created randomly, but which are based on a physically motivated area-per-depth distribution. Our reference topography used in this study is displayed in Fig. 4.

The area-per-depth distribution is based on a geological modelling study by Flament et al. (2008) assuming a $200 \mathrm{~K}$ hotter mantle as well as $20 \%$ continental crust compared to today's value. The latter is the smallest value of their range ( 20 to $80 \%$ ) for the period between 4 and $2.5 \mathrm{Ga}$. For the mode of mantle cooling and thus the age distribution of the oceanic lithosphere, we have chosen the model by Labrosse and Jaupart (2007) (named LJ07 in Flament et al., 2008). As it is the medium value out of the suggested range, we have picked a maximum age of the ocean floor of $142 \mathrm{Ma}$. As can be seen in Fig. 3 in Flament et al. (2008), the resulting emerged surface area under the assumption of presentday maximum orography height turns out to be about $3 \%$ of the Earth's surface. Estimating the dynamically supported maximum elevation to be $3600 \mathrm{~m}$ as suggested by Rey and Coltice (2008) for the Neoarchean leads to a modified value for the emerged surface area of about $1 \%$. Our random reference topography follows the resulting depth distribution of submerged continental crust, continental slope and oceanic lithosphere which is shown in Fig. 5.

In order to ensure that our results do not significantly depend on the choice of the reference topography, we have performed simulations with two additional random 


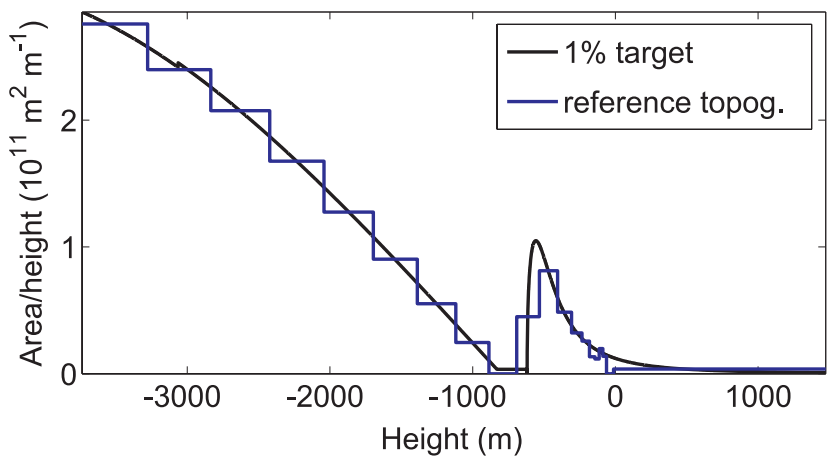

Fig. 5. Area-per-depth distribution used in the simulations of the early Archean. The black line represents the physically motivated distribution, and the blue line shows the actual distribution underlying the discrete model topography field.

topographies that are also characterised by $1 \%$ emerged surface, two topographies whose continents are distributed as archipelagos (once near the equator, once in a polar location) and three topographies with $5 \%$ emerged surface. In Sect. 5.1, we describe the overall differences to the reference case.

\subsection{Solar constant, orbital parameters, rotation rate and atmospheric composition}

As this study focuses on the early Archean, the solar constant in the model has been reduced by $25 \%$ to $1024 \mathrm{~W} \mathrm{~m}^{-2}$ (cf. Sect. 1). The orbital parameters of the Earth are fixed to the values of the year 1950 (Berger, 1978). As already indicated in Sect. 2.3.3, the rotation rate of the Earth has been fixed to 1.6 times its present-day value. Regarding atmospheric composition, we apply different $\mathrm{CO}_{2}$ partial pressures (cf. Sect. 3.3) in addition to a nitrogen $\left(\mathrm{N}_{2}\right)$ partial pressure of 0.8 bar. Rayleigh scattering has been adjusted to respect changes in the $\mathrm{CO}_{2}$ concentration (Plattner et al., 2008), and the impact of differences in total atmospheric pressure is taken into account in the long-wave radiation module as well as indirectly in the calculation of the tropopause height. However, changes in the heat capacity of air due to deviations in the total atmospheric pressure from the present-day value are neglected in the calculation of atmospheric heat transport. Furthermore, the almost complete absence of ozone in the Archean atmosphere has been neglected - an effect that is not expected to have a major influence ( $2 \mathrm{~K}$ global SAT increase in the simulations by Jenkins, 1995).

\subsection{Overview of model simulations}

In this paper, a significant number of simulations have been performed, especially in the course of the uncertainty studies in Sect. 5.

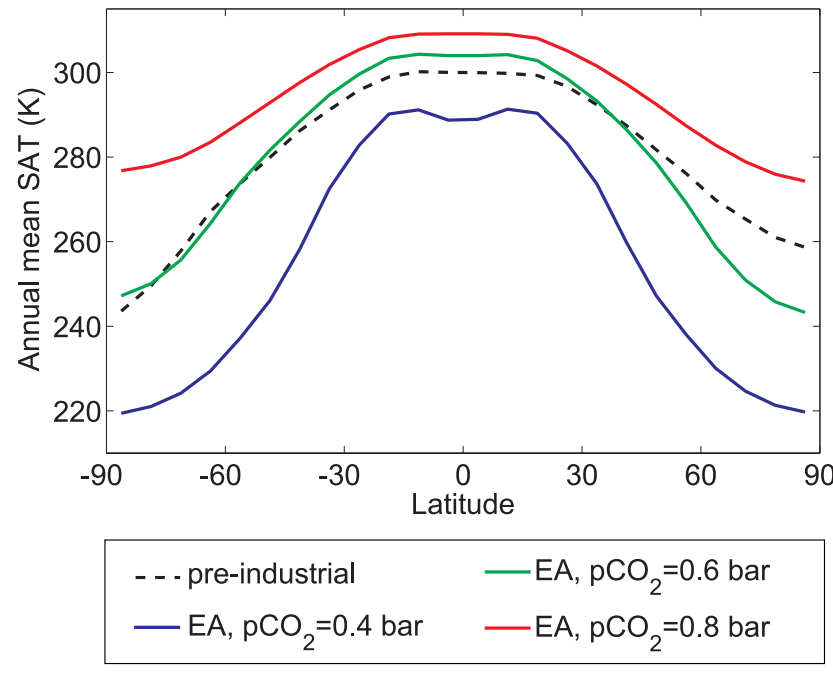

Fig. 6. Annual and zonal mean SAT for the following states: pre-industrial (black), the critical state of the early Archean $\left(~ p \mathrm{CO}_{2}=0.4\right.$ bar, blue), the state of the early Archean with presentday mean SAT of $288 \mathrm{~K}\left(p \mathrm{CO}_{2}=0.6 \mathrm{bar}\right.$, green $)$ and an ice-free state $\left(p \mathrm{CO}_{2}=0.8\right.$ bar, red $)$.

The main climate states that are analysed in more detail in this paper are three simulations of the early Archean as well as a present-day reference state. The three simulations of the early Archean apply the boundary conditions described above as well as $\mathrm{CO}_{2}$ partial pressures of $0.4,0.6$ and 0.8 bar. These values were chosen because they correspond to the critical state, a climate with an annual mean SAT similar to today and an ice-free planet, respectively.

\section{Characteristics of three early Archean climate states}

In the following, we will examine the characteristics of three states with early Archean boundary conditions: the critical state $\left(p \mathrm{CO}_{2}=0.4 \mathrm{bar}\right)$, a state with present-day global mean temperature $\left(p \mathrm{CO}_{2}=0.6 \mathrm{bar}\right)$ and an ice-free state $\left(p \mathrm{CO}_{2}=0.8\right.$ bar, $300 \mathrm{~K}$ mean SAT $)$.

The surface air temperature field results from an interplay of the insolation distribution, the 2-D albedo field and the greenhouse effect, with further modification due to the heat transport processes in the ocean and in the atmosphere. The latitudinal profile of the surface air temperatures is shown in Fig. 6. Note the strong cooling influence of sea ice in the polar regions for the colder climate states.

In the following, we will have a more detailed look at the effects which determine the SAT profile.

\subsection{Surface and planetary albedo}

At first order, the global energy balance of the Earth in different climate states is determined by the albedo and its latitudinal changes. Figure 7 shows the latitudinal distribution of 

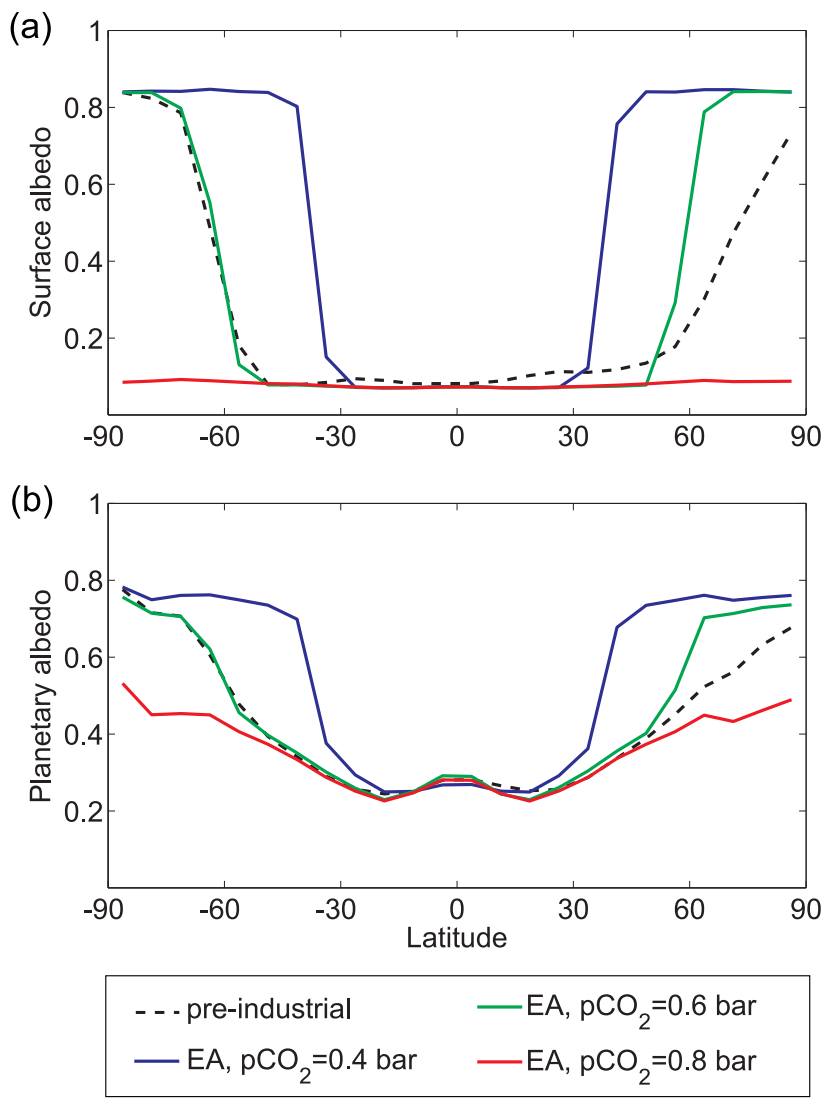

Fig. 7. Annual and zonal mean surface and planetary albedo for the following states: pre-industrial (black), the critical state of the early Archean $\left(~ p \mathrm{CO}_{2}=0.4\right.$ bar, blue $)$, the state of the early Archean with present-day mean SAT of $288 \mathrm{~K}\left(p \mathrm{CO}_{2}=0.6 \mathrm{bar}\right.$, green $)$ and an icefree state $\left(p \mathrm{CO}_{2}=0.8 \mathrm{bar}\right.$, red $)$.

annual mean surface as well as total planetary albedo for all four states. The two main reasons for variations in albedo are differences in sea-ice cover (with impact on the surface and planetary albedo) and changes in cloud cover (directly impacting only the planetary albedo). Clouds are a considerable source of uncertainty in model simulations (Stephens, 2005; Cesana and Chepfer, 2012) but can have a significant impact on the energy balance of the Archean Earth (Goldblatt and Zahnle, 2011). At the same time, simulations of the sea-ice albedo feedback are more reliable. Furthermore, the significantly smaller continental fraction in the early Archean implies a reduction of surface albedo in snow-free regions compared to climate states with present-day topography. These factors will be discussed in more detail in the following.

\subsubsection{Surface albedo and sea-ice cover}

As the Earth in our simulations of the early Archean is covered almost completely with water, its surface albedo profile in Fig. 7 is very steep near the ice-boundary. Remarkably, the ice line for the early Archean $288 \mathrm{~K}$ state is very similar to the Southern Hemisphere ice boundary in the present-day climate, which is caused by the presence of the Antarctic continent. The reason for the early Archean state being as warm as the present-day state, even though an annual mean ice-line at such a low latitude is also present in the Northern Hemisphere, lies in the higher equatorial temperatures. We further observe that the sea ice is almost completely covered by snow, even for the critical state which exhibits a low sea-ice boundary of $34^{\circ}$ (defined by $10 \%$ annual mean seaice cover). This results in a very high polar surface albedo, even higher than the planetary albedo that is limited by atmospheric absorption. The global mean surface albedo amounts to 0.37 for the critical state in contrast to 0.12 for today's climate state and this implies a substantial global cooling.

In order to judge the impact of the topography on surface albedo, two comparisons are instructive: first of all, a state with fixed present-day surface types and topography but without sea ice ( $S=0.75 \times S_{0}, p \mathrm{CO}_{2}=0.8 \mathrm{bar}, \Omega=1.0$ ) has a mean surface albedo of 0.11 compared to only 0.07 for our ice-free early Archean topography. And secondly, the early Archean surface albedo in the always ice-free equatorial region (between $34^{\circ} \mathrm{N}$ and $34^{\circ} \mathrm{S}$ ) is reduced from 0.09 to 0.07 compared to the present-day topography (numbers based on the two states with mean SAT of $288 \mathrm{~K}$ ) which is a relatively small difference. The overall impact of our early Archean topography on the surface albedo is therefore comparatively small.

\subsubsection{Planetary albedo and clouds}

The planetary albedo is more complicated than the surface albedo due to the contributions of clouds. Clouds, however, play an important role not only by means of changes to the planetary albedo and the direct warming due to the absorption of long-wave radiation, but also indirectly by modifying the LWR spectrum and thus influencing the greenhouse effect of different gases: Goldblatt and Zahnle (2011) find that the greenhouse effect of $\mathrm{CO}_{2}$ is overestimated by 20 to $25 \%$ in model simulations of the Archean climate that completely neglect clouds (for $p \mathrm{CO}_{2}$ between 0.01 and $0.1 \mathrm{bar}$ ).

The latitudinal profiles of stratus and cumulus clouds in the simulated early Archean climate states are shown in Fig. 8. Differences in cloud fraction between the states are strongest in the tropics. There, but not restricted to this area, colder temperatures lead to a larger stratus cloud and a lower cumulus cloud fraction and vice versa. The differences in stratus clouds turn out to be much larger than the differences in cumulus clouds so that they dominate the results for the total cloudiness.

The stratus cloud fraction in our model has an explicit $r^{1.5}$ dependency on relative humidity $r$ which decreases for an unchanged water mass if temperature and thus saturation humidity increase. This is consistent with results by Yang et al. (2012b), who find overall smaller fractions of low-level 


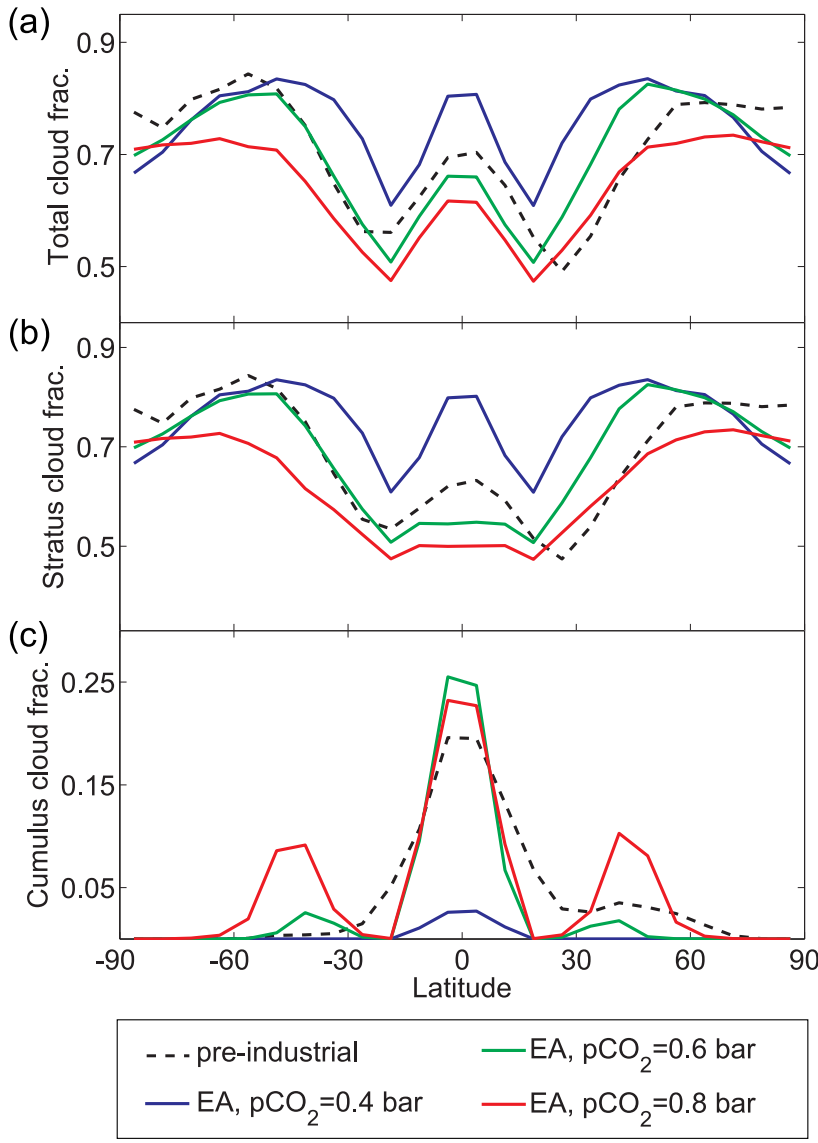

Fig. 8. Annual and zonal mean total cloud fraction in the preindustrial climate and the three early Archean climate states: (a) total fraction, (b) stratus cloud fraction, (c) cumulus cloud fraction.

clouds (between the surface and the level of $700 \mathrm{hPa}$ ) for warmer states.

In contrast to this, the cumulus cloud fraction does not fundamentally depend on relative humidity but is instead determined by a combination of effective vertical velocity and specific humidity. The latter must reduce in case of lower temperatures due to the smaller saturation humidity, thus explaining the changes in cumulus cloud fraction described above.

The latitudinal distribution of clouds is in total strongly influenced by the atmospheric cell boundaries, as can be seen in Fig. 8 from the minima in cloud fraction that have shifted from 30 to $22.5^{\circ}$ in concordance with the high pressure area at the boundaries between the Hadley and Ferrel cells. This shift reflects the higher rotation rate of the Earth in the early Archean and takes place near the sea-ice boundary of the critical state, a region in which the local energy balance is especially important in determining the critical $\mathrm{CO}_{2}$ partial pressure and the maximum stable sea-ice extent.

While the shape of the total cloud fraction profile for the critical state approximately resembles the results by Jenkins

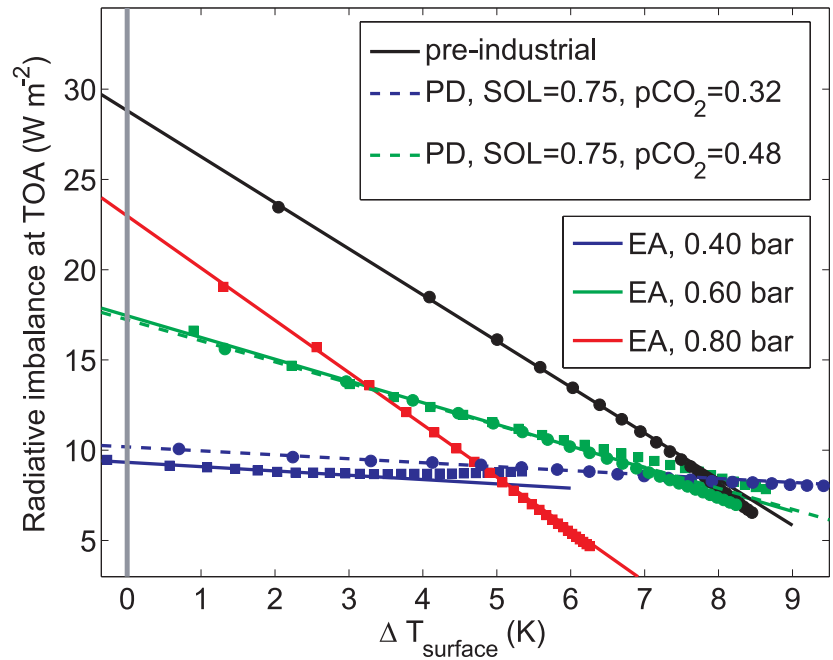

Fig. 9. Radiative imbalance at the top of the atmosphere when all clouds are removed instantaneously in different equilibrium climate states. Each point in the scatter plot corresponds to the mean value of one year. The linear fits are based on the first $9 \mathrm{yr}$ in all cases. The simulation of the pre-industrial climate has been performed with the model version including the technical changes as in Sect. 2.4. Note that the $\mathrm{x}$-axis represents surface and not surface air temperature.

(1993a) for a state with similar temperature, higher rotation rate and zero land-fraction (though higher solar constant), our simulated cloud fractions are overall larger, especially in the polar regions. This difference in the high latitudes is consistent with the tendency of our model for the present-day climate compared to the CMIP5-models described in Sect. 2.2.

The differences in clouds between the present-day state and the three early Archean states have an impact on the planetary albedo as well as on the long-wave radiation. It is therefore desirable to quantify their impact on Earth's energy balance. Of course, the radiative forcing (e.g. Hansen et al., 2005; Forster et al., 2007) due to clouds and their impact on surface temperature strongly depends on the different properties of the climate states, so that we can only point out which radiative contribution the simulated clouds give to our three early Archean reference states, compared to the impact clouds have under pre-industrial boundary conditions.

In a set of experiments, we have instantaneously removed all clouds in different equilibrium states. The resulting total net radiative imbalance at the top of the atmosphere (TOA) is plotted against global mean temperature in Fig. 9, and the results for the first nine years are linearly extrapolated to zero temperature change in order to receive the initial radiative forcing. We thus in principle follow the method by Gregory et al. (2004). The radiative imbalance is positive in all cases, which implies that the clouds were cooling the climate system and that their removal leads to warming. However, in the absence of clouds, less long-wave radiation is absorbed by the atmosphere so that it first cools even though the surface absorbs additional short-wave radiation. Therefore, it is not 
possible to deduce the initial radiative forcing from extrapolation to zero surface air temperature. Thus, in contrast to Gregory et al. (2004), we instead base our analysis on surface temperature. This is justified because we find a linear relationship for the first simulated years (Fig. 9).

Under pre-industrial conditions, the radiative forcing corresponding to a removal of the clouds is $28.8 \mathrm{~W} \mathrm{~m}^{-2}$ (black line). This is in stark contrast to $17.2 \mathrm{~W} \mathrm{~m}^{-2}$ in the case of a climate state with a solar insolation reduced to $75 \%$, present-day topography and a similar global mean SAT of $288 \mathrm{~K}$ which can be reached when $p \mathrm{CO}_{2}=0.48$ bar is applied (green dashed line). The difference is obviously caused by the fact that the main impact of the clouds is an increase of planetary albedo, which has a larger effect in terms of radiative forcing if the solar insolation is higher. With respect to the three states of the early Archean, we observe that the radiative effect resulting from a removal of the clouds is smaller for colder states $\left(9.3,17.5\right.$ and $23.0 \mathrm{~W} \mathrm{~m}^{-2}$ for the three states with $p \mathrm{CO}_{2}$ of $0.4,0.6$ and 0.8 bar, respectively). This is the case even though there are more clouds in the colder states, and it can be explained by the fact that the impact of clouds on the total, planetary albedo is reduced if there is already a high albedo due to the presence of sea ice.

We can conclude that the clouds simulated with our model provide a net cooling of the climate system and that differences in the strength of this effect between our four reference states (pre-industrial and early Archean) are predominantly caused by differences in solar radiation and seaice amount. These differences in cloud radiative forcing are much larger than those between climate states that have a similar temperature or sea-ice fraction (illustrated by the use of identical colour in Fig. 9) but differ with respect to rotation rate and continental fraction (solid lines for early Archean and dashed lines for present-day boundary conditions): $9.3 \mathrm{~W} \mathrm{~m}^{-2}$ vs. $10.2 \mathrm{~W} \mathrm{~m}^{-2}$ for the critical states, and $17.5 \mathrm{~W} \mathrm{~m}^{-2}$ vs. $17.2 \mathrm{~W} \mathrm{~m}^{-2}$ for the states with a mean SAT of $288 \mathrm{~K}$.

As the contributions of cumulus clouds to the total radiative forcing are very small, ranging between 1 and $9 \%$, we do not analyse the differences between simulated cumulus and stratus clouds in detail.

Note that these radiative forcing values alone cannot be directly related to the equilibrium temperature changes finally resulting from the removal of clouds because feedback mechanisms as the ice-albedo effect act on longer timescales and differ between the states (cf. Fig. 9).

\subsection{Lapse rate}

A further substantial impact on surface air temperature is provided by changes in the lapse rate. For fixed effective radiative temperature and effective radiative height, a lower lapse rate implies a lower surface air temperature. In our model, the 2-D lapse rate field explicitly depends on temperature and humidity. The lapse rate is therefore coupled to

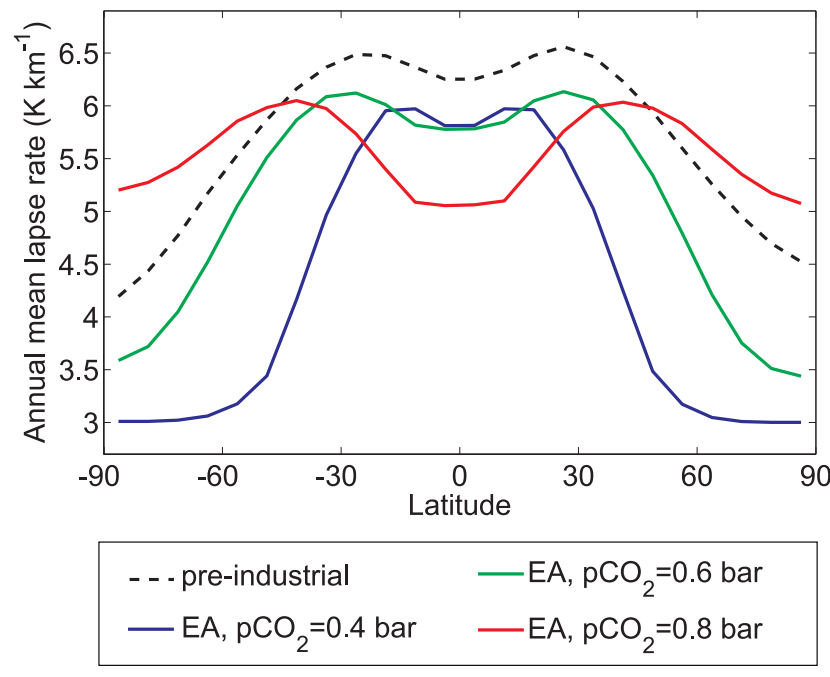

Fig. 10. Annual and zonal mean lapse rate for the following states: pre-industrial with the technical modifications from Sect. 2.3.3 (black), the critical state of the early Archean $\left(p \mathrm{CO}_{2}=0.4 \mathrm{bar}\right.$, blue), the state of the early Archean with present-day mean SAT of $288 \mathrm{~K}\left(p \mathrm{CO}_{2}=0.6 \mathrm{bar}\right.$, green $)$ and an ice-free state $\left(p \mathrm{CO}_{2}=0.8 \mathrm{bar}\right.$, red).

changes in, e.g. sea-ice formation while it is (sometimes only in the lower levels) kept fixed at the adiabatic values in many studies with 1-D models (e.g. Kasting et al., 1984; Goldblatt et al., 2009). Figure 10 shows the differences in lapse rate between the three simulated early Archean climate states and the pre-industrial state which already includes our modifications regarding lapse rate calculation (cf. Sect. 2.3.3) and compares well with observational data (Stone and Carlson, 1979). From Eq. (3), we see that the lapse rate increases with increasing temperature and decreases with rising humidity. Figure 10 shows the significantly lower lapse rate of the colder states in high latitudes, which is consistent with a positive temperature feedback. We observed that the situation is different in the warmer, equatorial regions where the negative feedback due to the water vapour term dominates: warmer states with more water vapour show a lower lapse rate, thus decreasing surface air temperature.

As the lapse rate regionally differs by up to about $2 \mathrm{~K} \mathrm{~km}^{-1}$, the impact on surface air temperatures is up to around $20 \mathrm{~K}$ with an effective radiative height of about $10 \mathrm{~km}$. Due to the opposite effects in equatorial and polar regions, the lapse rate changes contribute to a further steepening of the temperature profile in the course of a cooling climate. This facilitates sea-ice formation in the higher latitudes and thus acts towards increasing the critical $\mathrm{CO}_{2}$ partial pressure while at the same time it stabilises low latitude seaice boundaries. 


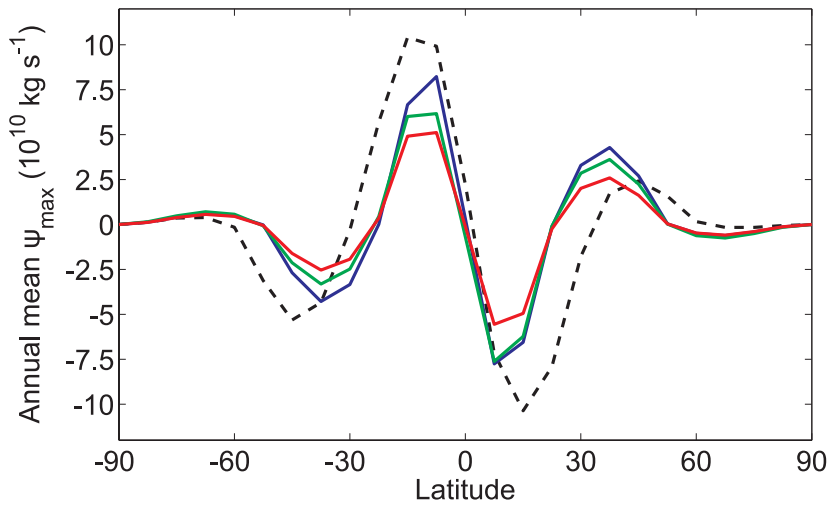

$$
\begin{array}{|l}
\hline \text { - - pre-industrial } \\
\text { - } \mathrm{EA}, \mathrm{pCO}_{2}=0.4 \mathrm{bar} \quad-\mathrm{EA}, \mathrm{pCO}_{2}=0.6 \mathrm{bar} \\
\hline
\end{array}
$$

Fig. 11. Maxima of the atmospheric meridional stream functions for the pre-industrial state (black) and the three states of the early Archean (EA).

\subsection{Atmospheric dynamics}

Large-scale atmospheric and oceanic dynamics are amongst the most important characteristics of the climate system. They play a significant role in setting up horizontal heat transport and thus interact with the radiative balance in determining the planet's temperature field.

The dynamic state of the atmosphere is given by the meridional circulation cells, the zonal winds as well as the azonal component. In our model, the mean cell boundaries are prescribed (cf. Sect. 2.3.2), but their seasonal fluctuations as well as their strengths depend on the temperature field. Figure 11 shows annual mean maxima of the stream functions, thus illustrating the cell boundaries located closer to the equator, the symmetry between the two hemispheres and the changes in strength. All states of the early Archean have lower cell strengths than the pre-industrial reference case. The cell strengths are the combined effect of a different temperature field in the absence of larger continents and the modified cell strength parameters (Table 1). The latter have been chosen such that they provide the cell strengths from Marshall et al. (2007) when their aquaplanet temperature field is applied; and the maxima of the stream functions for the partially glaciated state are not too different from the results by Marshall et al. (2007) even though the temperature field is determined not only by the aquaplanet conditions but also by the other changes to early Archean boundary conditions.

The warmer Archean states show a lower strength because the reduction in the temperature difference between the cell boundaries has a dominant effect over the general warming (cf. the proportionality to $T_{i}^{3} \times \Delta T$ in Eq. 1). Though under different boundary conditions, this temperature dependency of the Hadley cell strengths is qualitatively confirmed by a set

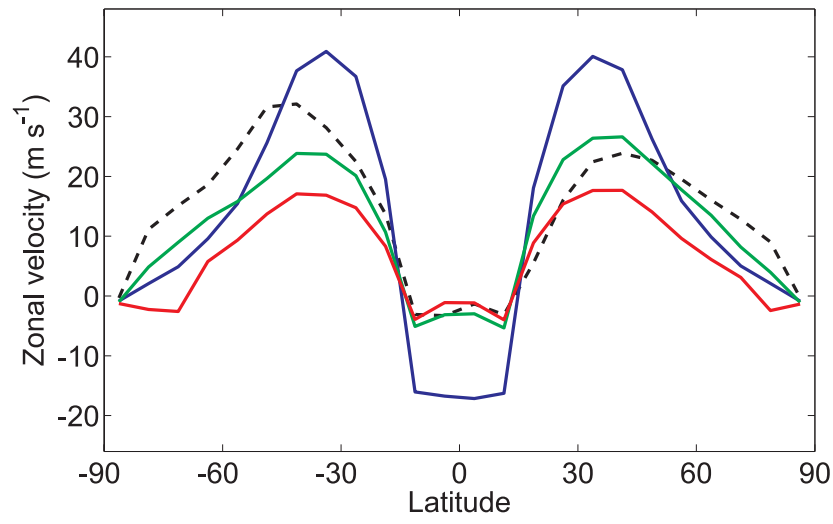

$$
\begin{aligned}
& \text { - - pre-industrial } \quad-\mathrm{EA}, \mathrm{pCO}_{2}=0.6 \mathrm{bar} \\
& -\mathrm{EA}, \mathrm{pCO}_{2}=0.4 \mathrm{bar} \quad-\mathrm{EA}, \mathrm{pCO}_{2}=0.8 \mathrm{bar}
\end{aligned}
$$

Fig. 12. Latitudinal profile of the annual-mean zonal wind maxima (taken with respect to height) for the pre-industrial state (black) and the three states of the early Archean (EA).

of experiments with varying solar irradiance by Yang et al. (2012a).

The maxima of the annual-mean zonal winds are shown in Fig. 12. They are consistently shifted equatorwards and the relative order of strengths reflects the meridional cell strengths which set the pressure and wind-stress fields. With respect to these wind speeds, the simulation applying $p \mathrm{CO}_{2}=0.6$ bar is most similar to the aquaplanet simulation by Marshall et al. (2007) which assumes present-day $\mathrm{CO}_{2}$ and solar forcing and exhibits a sea-ice boundary of $55^{\circ}$. The azonal component of the wind is not explicitly depicted here, but it is implicitly taken into account in the atmospheric heat transport discussed in Sect. 4.5.

\subsection{Ocean dynamics}

Due to the almost negligible land fraction, the ocean circulation was entirely different in the early Archean compared to today. Under present-day topography, the overturning circulation as well as horizontal currents contribute to heat transport and are thus important for the planet's energy balance.

In the absence of significant land masses, the meridional overturning circulation mainly consists of symmetric cells (Fig. 13). In contrast to today's thermohaline circulation, they mirror the atmospheric cells in the early Archean because of the wind stress acting as the driver. This circulation is expected to show similarities with aquaplanet simulations because of the small land fraction, while differences and asymmetries may of course arise due to the non-uniform random ocean depth as well as the differences in further boundary conditions. The aquaplanet simulations by Marshall et al. (2007) under present-day radiative forcing indeed show a shallow, wind-driven oceanic overturning circulation with 

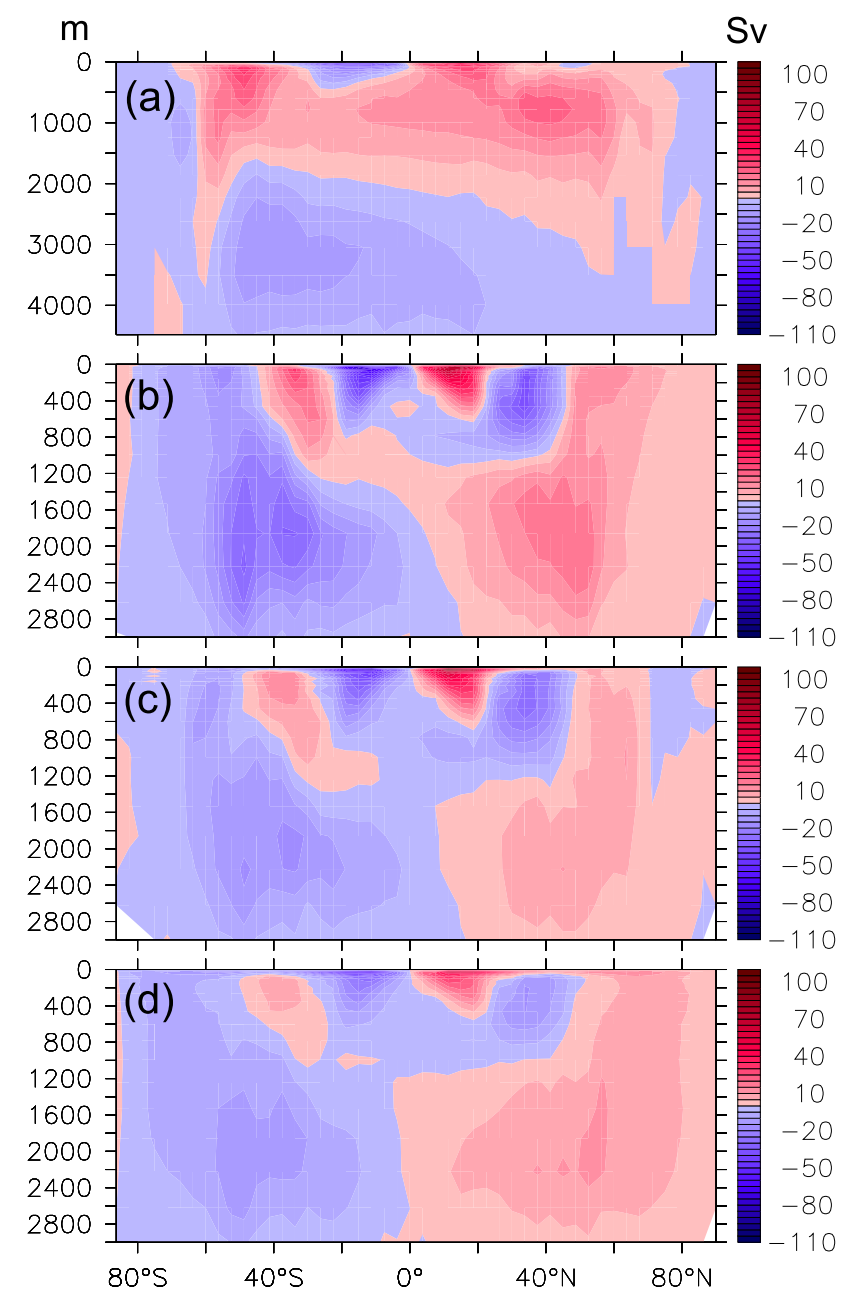

Fig. 13. Oceanic overturning stream functions for the pre-industrial climate state (a) and the three early Archean states $-\mathrm{CO}_{2}$ partial pressure of $0.4,0.6$ and 0.8 bar in (b), (c) and (d) respectively.

the location of the cells corresponding to the atmosphere as in our simulations of the Archean. In their as well as in our simulations, the majority of the transport by the strong circulation cells adjacent to the equator is located in the upper $600 \mathrm{~m}$. The transport of these cells (maxima of annual mean stream function) turns out to be $81 \mathrm{~Sv}\left(p \mathrm{CO}_{2}=0.4 \mathrm{bar}\right)$, $99 \mathrm{~Sv}\left(p \mathrm{CO}_{2}=0.6\right.$ bar $)$ and $71 \mathrm{~Sv}\left(p \mathrm{CO}_{2}=0.8\right.$ bar $)$ and is therefore larger in all three early Archean simulations than in Marshall et al. (2007) under present-day forcing (about $60 \mathrm{~Sv})$. Furthermore, the transport below the top grid cell of the model $(25 \mathrm{~m}$ deep) is mostly in the opposite direction of the relatively strong surface currents and reaches deeper when the currents are stronger. While the meridional surface velocities without the Gent-McWilliams (GM) component are larger when the state is colder (corresponding to the order of wind velocities), the total transport is affected by the poleward GM velocities which are largest in the $288 \mathrm{~K}$ state.

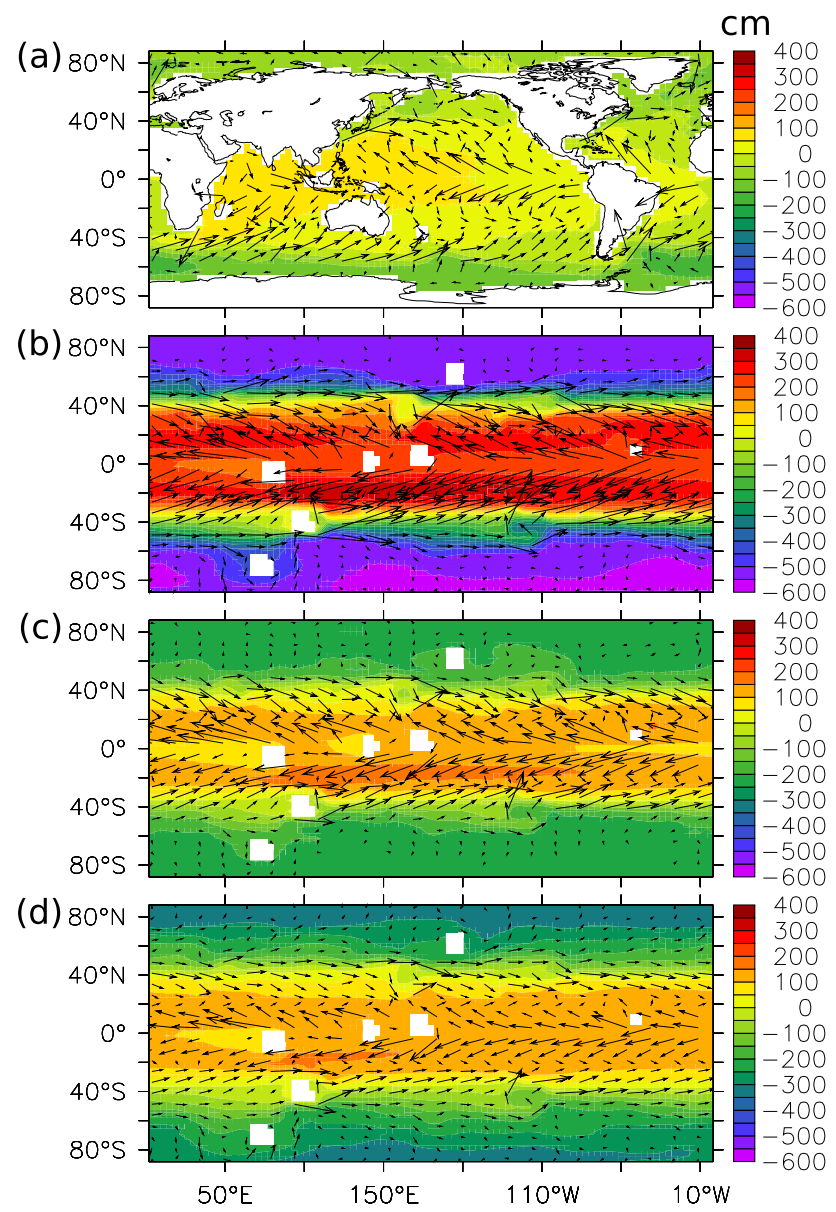

Fig. 14. Oceanic surface velocities (arrows) on top of sea-surface height anomalies (colour shading) for the pre-industrial climate state (a) and the three early Archean states $-\mathrm{CO}_{2}$ partial pressure of $0.4,0.6$ and 0.8 bar in (b), (c) and (d) respectively. The relative lengths of the arrows correspond to the relative magnitudes of the velocities.

The surface velocities have a very characteristic structure under present-day topography, e.g. producing the large and strong subtropical gyres. However, in case of very small land fraction they closely resemble a purely zonal flow (Fig. 14). For the early Archean topography, the strength of the surface velocities (Fig. 15) is correlated with the strength of the atmospheric meridional cells. The surface velocities for the state with a $\mathrm{CO}_{2}$ partial pressure of 0.6 bar reach about $0.25 \mathrm{~m} \mathrm{~s}^{-1}$ at the equator and about $0.16 \mathrm{~m} \mathrm{~s}^{-1}$ in midlatitudes. This is in contrast to the values of 0.8 and $0.2 \mathrm{~m} \mathrm{~s}^{-1}$ found by Marshall et al. (2007), which are not only overall higher but also show a high factor of 4 between currents corresponding to the easterly trade winds and mid-latitude westerlies. 


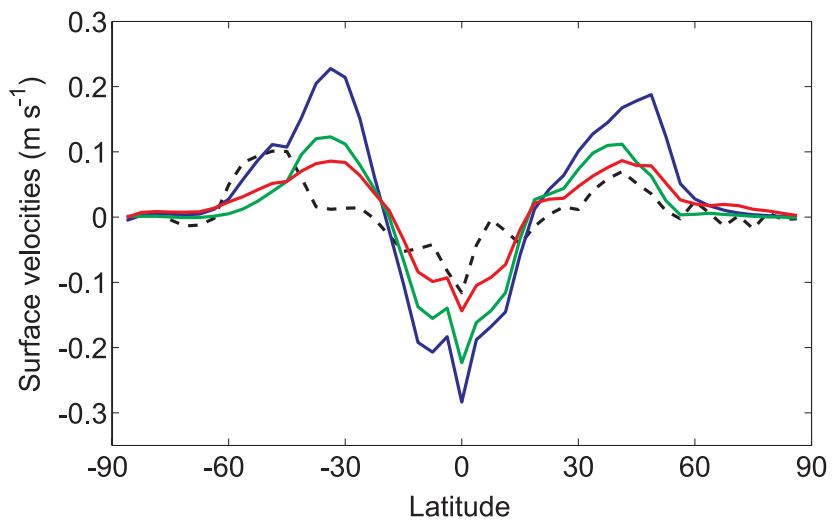

\begin{tabular}{l}
\hline - - pre-industrial $\quad-\mathrm{EA}, \mathrm{pCO}_{2}=0.6 \mathrm{bar}$ \\
$-\mathrm{EA}, \mathrm{pCO}_{2}=0.4 \mathrm{bar} \quad-\mathrm{EA}, \mathrm{pCO}_{2}=0.8 \mathrm{bar}$
\end{tabular}

Fig. 15. Oceanic surface velocities (annual and zonal mean) for the pre-industrial climate state as well as the three climate states of the early Archean.

\subsection{Heat transport}

The atmospheric and oceanic dynamics described above result in a meridional heat transport that is significant in determining the sea-ice boundary and thus the full global energy balance. Figure 16 shows the total heat transport as well as the oceanic and atmospheric contributions. Depending on the latitude, the oceanic contribution to the difference in heat transport between the pre-industrial and the early Archean climate (with $288 \mathrm{~K} \mathrm{SAT}$ ) is of a similar magnitude as the atmospheric contribution, which shows the relevance of using a full ocean model. In general, there is a reduction of atmospheric and of oceanic heat transport when going from the present-day state to the early Archean state with the similar global mean SAT and $p \mathrm{CO}_{2}=0.6$ bar. In the ocean, this is expected because of the reduction of the meridional overturning circulation due to the absence of continental boundaries. In the atmosphere, a reduction of advective heat transport in the tropics is found as well as a reduction of synoptic heat transport in the mid-latitudes of a similar magnitude. The increase of heat transport (in ice-free latitudes) with decreasing temperature and growing sea ice is consistent with the behaviour of ocean and atmosphere dynamics in Figs. 11 and 13.

The peak in total heat transport is not shifted by more than one model grid cell and is at either 33.75 or $37.5^{\circ}$ in the preindustrial simulation as well as in all three Archean simulations. Thus, the classic results of $35^{\circ}$ by Stone (1978) is also valid for our early Archean states.

The origins of the changes in heat transport are shown in Fig. 17 for climate states that are all characterised by $\mathrm{CO}_{2}$ partial pressures chosen such that they have about the same global mean SAT as the present-day climate (as well as the early Archean solar constant). Substituting the present-day

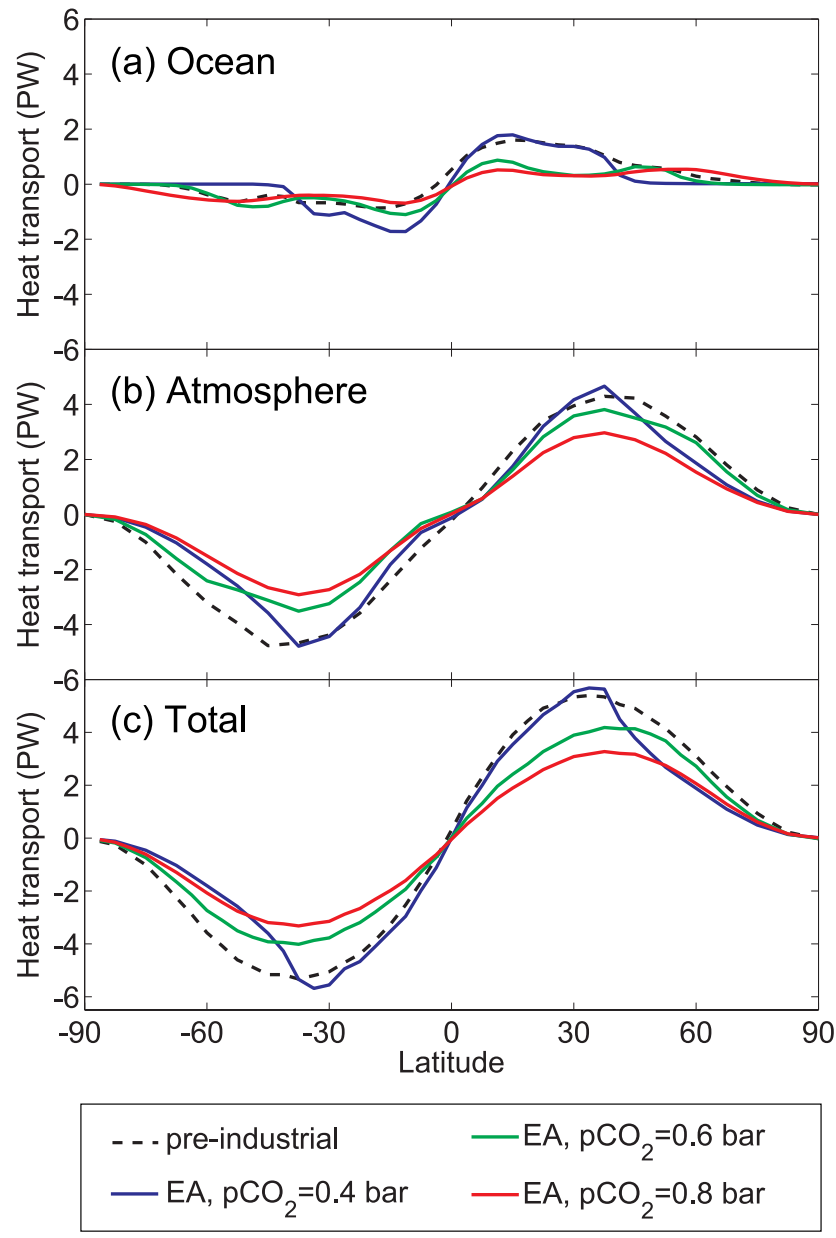

Fig. 16. (a) Oceanic, (b) atmospheric and (c) total meridional heat transport for pre-industrial conditions as well as for the three states of the early Archean (EA).

topography by the early Archean topography leads to an overall increase of oceanic heat transport. The opposite is true for an increase of the rotation rate to the early Archean value: meridional heat transport is reduced in almost all latitudes, and this is the dominant effect.

\section{Robustness of the results}

As described in Sect. 2, the largely unknown topography and the difficulties involved in determining long-wave radiative transfer in $\mathrm{CO}_{2}$-rich atmospheres constitute some uncertainty. The results presented in Sect. 4 are based on a specific reference topography and fixed parameters for the LWR scheme, and here we investigate the impact that different choices would have. Furthermore, our knowledge of the Archean rotation rate is not exact, and the values of sea-ice and snow albedo depend on the detailed conditions and lead to additional uncertainty. 


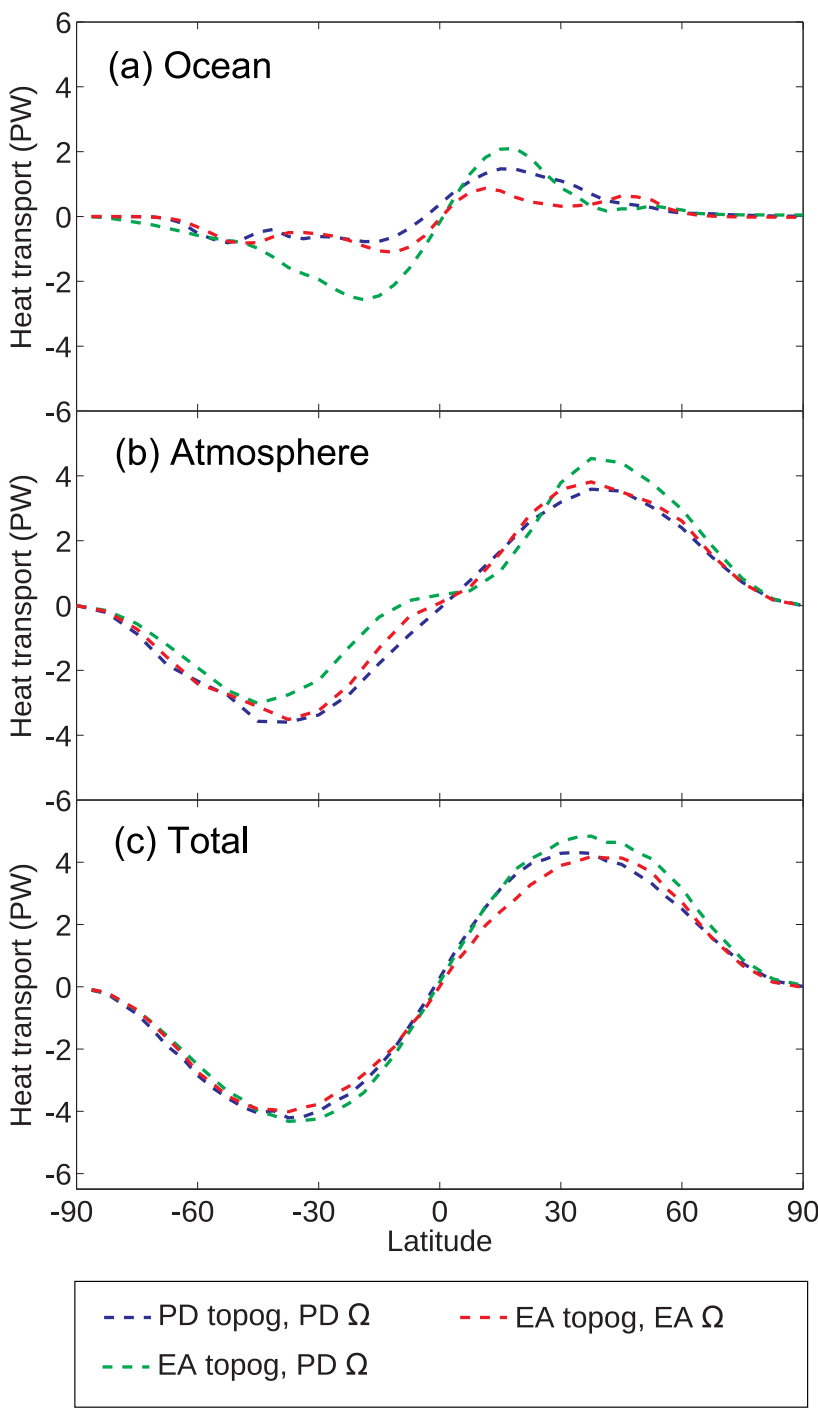

Fig. 17. (a) Oceanic, (b) atmospheric and (c) total meridional heat transport for three states with early Archean solar constant $(\mathrm{SOL}=0.75)$ and global mean SAT near the present-day value: present-day topography and rotation rate (blue, $p \mathrm{CO}_{2}=0.48$ bar), early Archean topography and present-day rotation rate (green, $p \mathrm{CO}_{2}=0.40$ bar), early Archean topography and rotation rate (red, $p \mathrm{CO}_{2}=0.60$ bar $)$.

\subsection{Topographies}

In order to understand the impact of topography, we still focus on the two states with $p \mathrm{CO}_{2}=0.60 \mathrm{bar}$ and $p \mathrm{CO}_{2}=0.80$ bar as in the analysis above. But as the critical state with $p \mathrm{CO}_{2}=0.40$ bar is close to instability with respect to complete glaciation, we substitute it in this section by a state with $p \mathrm{CO}_{2}=0.45$ bar.

Figure 18 shows the latitudinal SAT profiles for the different topographies and for each of the three $\mathrm{CO}_{2}$ partial pressures. Three of the topographies are exemplarily depicted in Fig. 19.

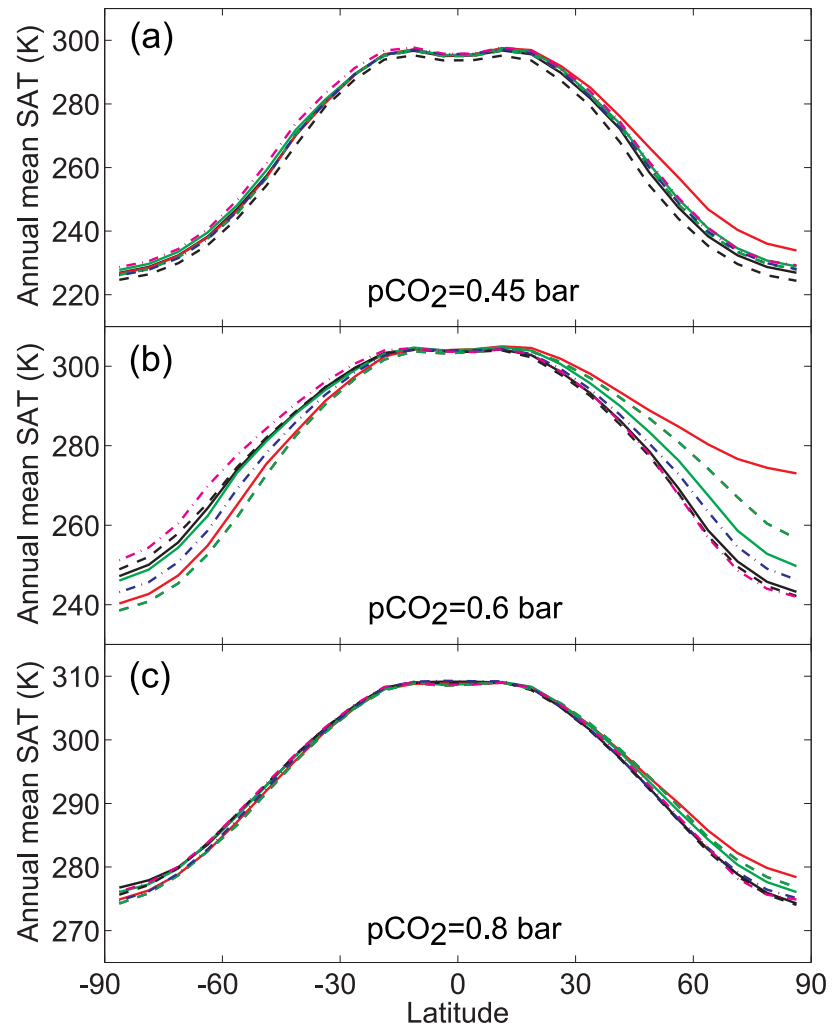

\begin{tabular}{|ll|}
\hline $1 \%$ emerged surface, C & $---5 \%$ emerged surface, A \\
$-1 \%$ emerged surface, D & $--5 \%$ emerged surface, B \\
$-1 \%$ emerged surface, $\mathrm{F}$ & $---5 \%$ emerged surface, $\mathrm{E}$ \\
-- equatorial archipelago & -- polar archipelago
\end{tabular}

Fig. 18. SAT profiles corresponding to the set of 7 different early Archean topographies for (a) $p \mathrm{CO}_{2}=0.45 \mathrm{bar}$, (b) $p \mathrm{CO}_{2}=0.60 \mathrm{bar}$ and (c) $p \mathrm{CO}_{2}=0.80$ bar.

The temperature differences among the various topographies are minor for the simulations with $p \mathrm{CO}_{2}=0.45$ bar and $p \mathrm{CO}_{2}=0.80$ bar, which implies that the sea-ice boundary is similar. We therefore find neither a significant dependence of the critical $\mathrm{CO}_{2}$ partial pressure nor of the state characteristics described in Sect. 4 on the topographies.

The situation is somewhat different for the simulation with $p \mathrm{CO}_{2}=0.60$ bar. Here, we find a much wider temperature spread as well as significant hemispheric asymmetries in some of the simulations. The latter are strongest in the topography $D$ with $1 \%$ emerged surface, which is ice-free in the Northern Hemisphere but has a mean sea-ice boundary of $49^{\circ}$ in the Southern Hemisphere. Already the ice-free case with a $\mathrm{CO}_{2}$ partial pressure of 0.8 bar shows higher temperatures at the North Pole than at the South Pole; for an overall colder climate in case of $p \mathrm{CO}_{2}=0.6 \mathrm{bar}$, this effect is enhanced by the ice-albedo feedback. The higher temperature in the Northern Hemisphere goes along with a higher northward heat transport compared to the other topographies, which again is due to a significantly larger northward ocean 
(a)

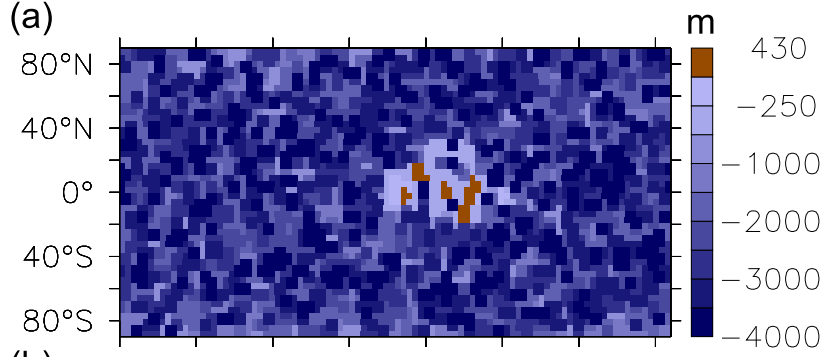

(b)

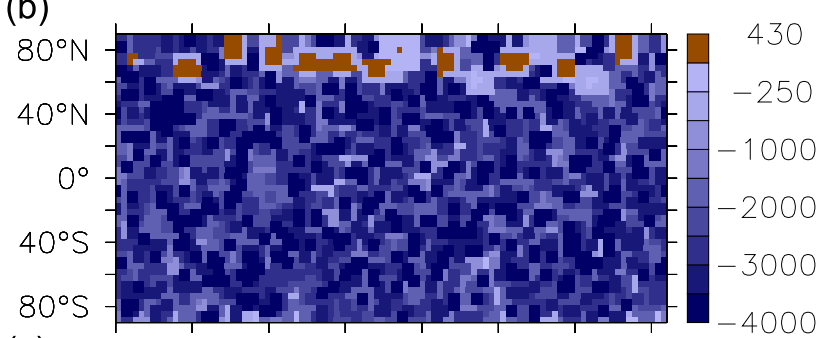

(c)

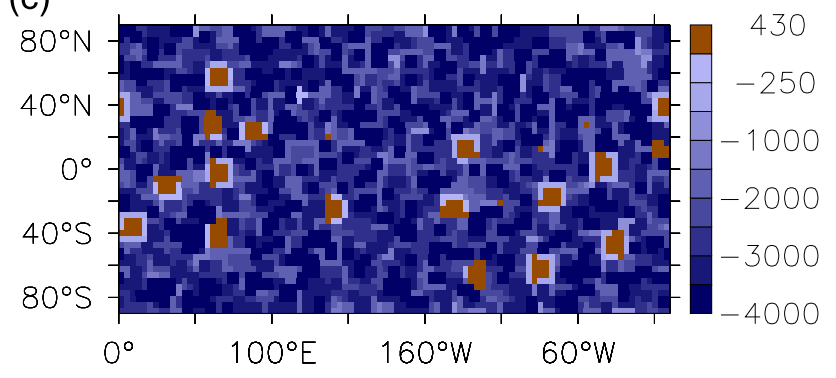

Fig. 19. Three exemplary topographies used in the uncertainty study: (a) equatorial archipelago, (b) polar archipelago and (c) a random topography with $5 \%$ instead of $1 \%$ emerged surface area.

heat transport (caused by the specific ocean bottom topography) which is not fully compensated by the weaker atmospheric transport.

In contrast to the impact of the ocean bottom topography on heat transport, the surface albedo difference appears to be negligible. For the ice-free state, we find global mean surface albedo values of $0.073-0.074$ for the topographies with $1 \%$ emerged surface (including the two archipelagos), and $0.077-0.078$ for those with $5 \%$ emerged surface depending on the latitudes of the continents. Indeed, the mean SAT of the five states with lower albedo is slightly higher than that of the states with higher albedo (299.8 K vs. $299.7 \mathrm{~K})$. But the difference is smaller than the spread among topographies of the same type, and we already see from Fig. 18 that those states with the slightly higher surface albedo are not necessarily warmer than those with a lower albedo value.

We can thus conclude that the impact on the results due to differences between our early Archean topographies is minor for the critical and ice-free states, but can result in asymmetries between the two hemispheres for partially ice-covered states because of changes in oceanic heat transport depending on bottom topography.

\subsection{LWR parameterization}

Further uncertainty in the climate simulations of the early Archean necessarily arises because the absorption of longwave radiation in $\mathrm{CO}_{2}$-rich atmospheres is not exactly known. As described in Sect. 2.3.1, we tuned the appropriate parameter $a$ of our LWR-module to approximate the MTCKD-parameterization (Clough et al., 2005; Halevy et al., 2009) ( $a=0.008)$. However, it is necessary to check which impact the choice of a different parameter would have on the critical $\mathrm{CO}_{2}$ amount.

In Kienert et al. (2012), it was already noted that the critical $\mathrm{CO}_{2}$ partial pressure is reduced from 0.40 to $0.28 \mathrm{bar}$ when changing $a=0.008$ to $a=0.010$, which is still about five times higher than critical partial pressures in studies with 1-D models (e.g. von Paris et al., 2008). The partial pressures needed to provide a mean SAT of $288 \mathrm{~K}$ and to provide an ice-free state are 0.4 and $0.55 \mathrm{bar}$, respectively. If we reduce the LWR parameter to a value of $a=0.006$ (cf. Fig. 2) in order to estimate the magnitude of the involved uncertainty and thus approximate the approach by Meadows and Crisp (1996) (cf. CA parameterization in Halevy et al., 2009), we find a critical $\mathrm{CO}_{2}$ partial pressure of 0.65 bar. In that case, a partial pressure of 0.9 bar is required for a mean SAT similar to today and $p \mathrm{CO}_{2}=1.2$ bar to inhibit the formation of sea ice.

Even though it has been argued that previous simulations with 1-D models (that used a parameterization which is approximated by $a=0.010$ ) overestimated $\mathrm{CO}_{2}$-induced greenhouse warming (Wordsworth et al., 2010), the differences in temperature resulting from different parameter choices call for more detailed research on the radiative effect of $\mathrm{CO}_{2}$-rich palaeoatmospheres, in particular for laboratory experiments investigating the continuum absorption for conditions appropriate for early Earth.

\subsection{Sea-ice and snow albedo}

In simulations of Neoproterozoic glaciations, Yang et al. (2012a) have shown that the albedo values applied for sea ice and snow have a significant impact on the transition of the Earth towards a snowball state. The conditions of such a transition have been investigated in various studies based on models with different sea-ice settings. The results have been quite different, for example, with respect to the highest seaice fraction that still allows for a stable state without runaway glaciation. These differences have been partially attributed to the quite large range of sea-ice and snow albedo values applied in those models (Yang et al., 2012a).

The modelling studies analyzed by Yang et al. (2012a) use albedo values of $0.50-0.75$ for sea ice and $0.72-0.8$ for snow under freezing conditions. These ranges contain the results of quite recent measurements in the East Antarctic sea-ice zone (Brandt et al., 2005) which indicate an albedo of thick 


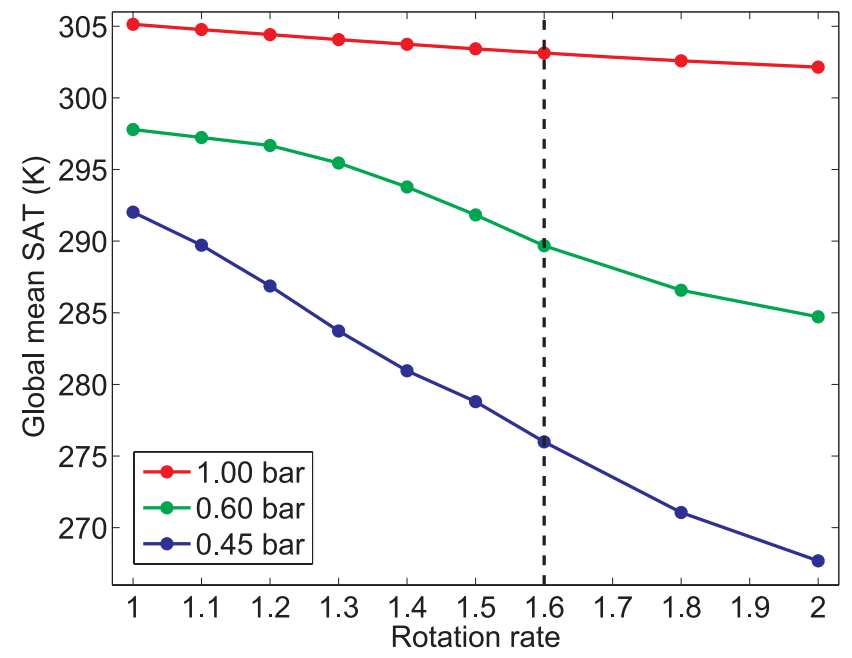

Fig. 20. Dependency of the global mean SAT on the Earth's rotation rate for three $\mathrm{CO}_{2}$ partial pressures of 0.45 bar (blue), $0.60 \mathrm{bar}$ (green) and $1.0 \mathrm{bar}$ (red). The early Archean rotation rate of $\Omega=1.6$ is marked with the black dashed line.

sea ice amounting to 0.49 and of snow amounting to values between 0.75 and 0.81 , varying between the seasons.

In accordance with the measurements by Brandt et al. (2005) as well as with the above model spread, we have varied the sea-ice albedo between 0.45 and the standard value of 0.72 as well as the value for snow between 0.75 and 0.85 in order to estimate the impact of these uncertainties on the critical $\mathrm{CO}_{2}$ partial pressures. It turns out that a change in sea-ice albedo has no effect on the critical partial pressure (within 0.01 bar) which is explained by the almost complete snow cover. In contrast, the variation in snow albedo causes the critical partial pressure of the early Archean to range between 0.32 and 0.47 bar so that this uncertainty should be kept in mind when comparing modelling results.

\subsection{Rotation rate}

Because of the strong interaction of the rotation rate with the sea-ice albedo effect, it is desirable to investigate the influence of uncertainties in our knowledge of the rotation rate on the critical $\mathrm{CO}_{2}$ concentration for the early Archean. In Kienert et al. (2012), we found a critical $\mathrm{CO}_{2}$ partial pressure of 0.4 bar for a rotation rate of $\Omega=1$.6. Under the assumption of angular momentum conservation in the Earth-Moon system, the uncertainty interval of the early Archean rotation rate ranges from $\Omega=1.3$ to $\Omega=1.8$ according to the analysis of tidal cycles in sediments (Williams, 2000).

Figure 20 shows the impact of rotation-rate changes between the present-day value $(\Omega=1.0)$ and double that value on the global mean SAT. For low $\mathrm{CO}_{2}$ partial pressure (blue line, $0.45 \mathrm{bar}$ ), the effect of a higher rotation rate strongly enhances the sea-ice albedo feedback, so that a state almost
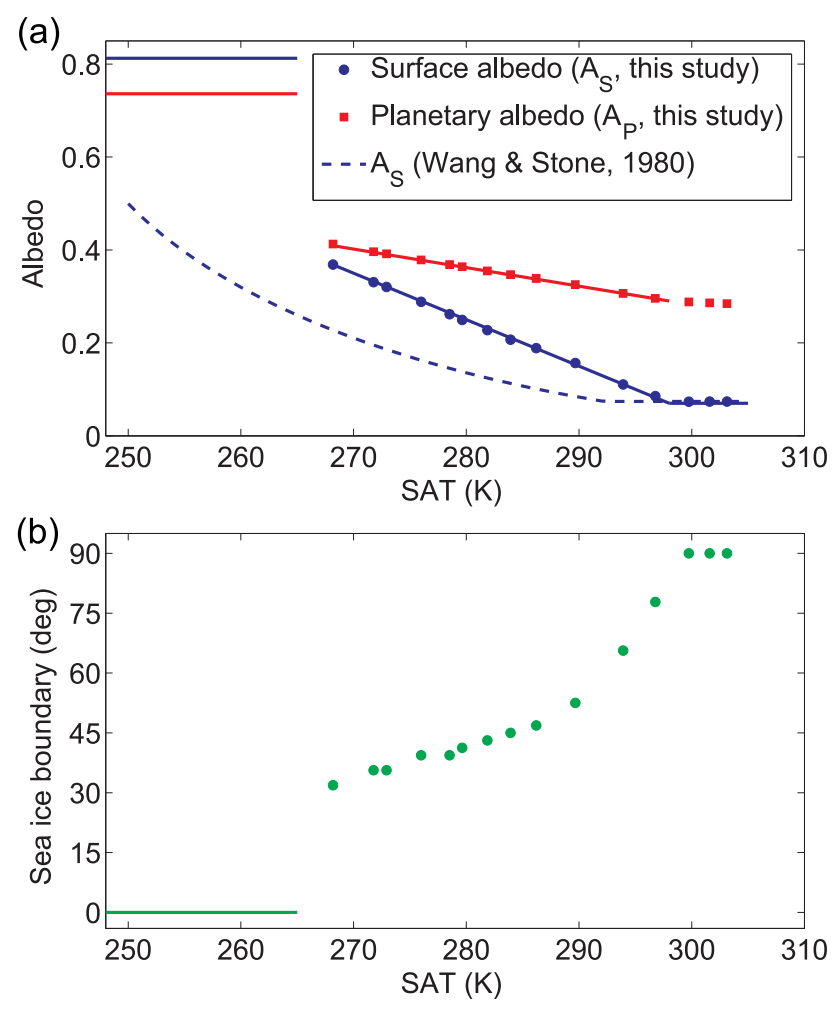

Fig. 21. Dependency of (a) surface and planetary albedo as well as (b) sea-ice boundary (mean of Northern and Southern Hemisphere values) on global mean SAT. The linear fits in (a) correspond to Eqs. (5) and (6). The constant albedo values for extremely low temperatures originate from a simulated snowball state. The dashed blue line in (a) shows the temperature dependence of the global mean surface albedo for present-day conditions according to Wang and Stone (1980) under the assumption of our snow and ocean albedo values.

ice-free at present-day rotation rate is brought close to a snowball Earth transition.

In a separate set of experiments, we have found the critical $\mathrm{CO}_{2}$ partial pressures corresponding to the uncertainty range of early-Archean rotation rates to be 0.36 and 0.43 bar. A different picture would emerge if the Earth's rotation rate was constant at 1.1 times its present value during the Precambrian due to resonance of atmospheric tides as has been suggested by Zahnle and Walker (1987): in that case, the critical $p \mathrm{CO}_{2}$ would have been only 0.34 bar. Thus, the impact of the uncertainty in the rotation rate is not negligible but does not change the qualitative picture either.

\section{Ice-albedo parameterization for radiative-convective models of the early Archean}

Earlier simulations of the climate of the Archean Earth have mainly relied on 1-D radiative-convective models. As these models allow for an efficient investigation of the radiative 
impact of more complex greenhouse gas mixtures and for studying atmospheric chemistry, they will certainly continue to play a role in research on the faint young Sun problem. Their largest shortcoming in determining the critical $\mathrm{CO}_{2}$ concentration required to prevent the Earth from freezing lies in the omission of the ice-albedo feedback (Kienert et al., 2012).

For climate states not too different from today, Wang and Stone (1980) have suggested using a parameterization of the albedo in terms of global mean temperature in these types of models. However, their relation is not expected to be valid for the early Archean because of the differences in surface type and meridional heat transport compared to today (cf. Sect. 4). Here, we suggest using the relation between global mean SAT and surface or planetary albedo from our model simulations as a more appropriate parameterization. This also implies that no ad-hoc assumption on the global mean SAT of the critical state is necessary anymore.

The relations found in our 3-D simulations (Fig. 21) exhibit an approximately linear behaviour and suggest the following approximations, where $\bar{T}$ is the global mean SAT in Kelvin:

$$
\begin{aligned}
& A_{\mathrm{S}}= \begin{cases}0.81, & \text { for } \bar{T}<268 \\
0.37-0.01 \times(\bar{T}-268) & \text { for } 268 \leq \bar{T} \leq 298 \\
0.07, & \text { for } \bar{T}>298\end{cases} \\
& A_{\mathrm{P}}=\left\{\begin{array}{ll}
0.74, & \text { for } \bar{T}<268 \\
0.41-0.004 \times(\bar{T}-268), & \text { for } 268 \leq \bar{T} \leq 298
\end{array} .\right.
\end{aligned}
$$

Both observed relations turn out to be poorly represented by linear approximations in the case of present-day rotation rate and are clearly non-linear for present-day continental topography. Therefore, one cannot expect this linearity to be a fundamental property. If one applies the Stefan-Boltzmann law to the global mean planetary albedo $\left(A_{\mathrm{P}}\right)$ and global mean effective temperature ( $\left.T_{\text {eff }}\right)$,

$\sigma T_{\mathrm{eff}}^{4}=\frac{1}{4} S_{0}\left(1-A_{\mathrm{P}}\right)$,

the relation is not far from linear in the relevant temperature range, but changes in lapse rate and effective radiative height may introduce non-linearity. From a different perspective, one can argue based on an approximation of the temperature and surface-albedo dependency on the sea-ice boundary (cf. Wang and Stone, 1980) that a purely geometric relation of sea-ice boundary and surface albedo without presence of land (as is almost the case for the early Archean) allows for a more linear behaviour in Fig. 21.

For comparison, we show the surface-albedo parameterization by Wang and Stone (1980) for the large range of global mean SAT between 250 and $305 \mathrm{~K}$ in Fig. 21a (dashed blue line, assuming our snow and ocean albedo values). The difference between this parameterization and the surface albedo in our simulations is significant, which underlines the advantage of using the relation based on our modelling results as a parameterization.

\section{Discussion}

In Sect. 4, we showed the surface and planetary albedo profiles of the simulated early Archean climate states. These properties play an important role for the energy balance of these states and for the high critical $\mathrm{CO}_{2}$ partial pressure reported in Kienert et al. (2012). In Sect. 5, we have demonstrated that a higher critical $\mathrm{CO}_{2}$ partial pressure is robust with respect to uncertainties in model parameters (radiative transfer, sea-ice and snow albedo) as well as boundary conditions (topography, rotation rate). The maximum sea-ice cover in our simulations corresponds to a sea-ice latitude of $34^{\circ}$. There is discussion in the literature, however, whether stable states with a narrow "waterbelt" close to the equator might exist.

The sea-ice boundary, and thus approximately the mean surface albedo, corresponding to a specific global mean surface temperature is determined by the latitudinal structure of radiation and heat transport. The stability of a critical state with a sea-ice boundary near the equator is, e.g. supported by comparatively high equatorial temperatures. Since the higher rotation rate of the early Archean indeed increases the equator-to-pole temperature difference compared to presentday rotation rate (cf. Kienert et al., 2012), this is a relevant contribution towards a critical sea-ice boundary at a lower latitude. On the other hand, the greenhouse radiative forcing, which compensates for the $25 \%$ reduction in solar luminosity, has a relatively uniform latitudinal distribution instead of a strong equatorial maximum like the insolation. All these boundary conditions are specific to the early Archean climate and contribute to the critical sea-ice boundary of $34^{\circ}$ in our simulations.

Note that the critical sea-ice latitude (and thus the albedo of the critical state) also depends on how sea ice is treated in the model. In general, it has been observed that runaway glaciation is more difficult (or even impossible) in models which employ a low sea-ice and/or snow albedo or neglect sea-ice dynamics. One palaeoclimate problem for which these effects have been studied are "snowball Earth" glaciations during the Neoproterozoic. The sea-ice boundary for a soft snowball Earth state (continental glaciation at the equator) was found to be $25^{\circ}$ in an atmospheric GCM with a mixed-layer ocean (bare sea-ice albedo between 0.6 and 0.7 ; Hyde et al., 2000). This value approximately corresponds to results of a more complex, fully coupled atmosphere-ocean general circulation model amounting to about $27^{\circ}$ for Marinoan as well as present-day continental boundary conditions (Voigt et al., 2011; Voigt and Marotzke, 2010). In contrast to this, simulations with the CAM model (Collins et al., 2004) find a stable sea-ice boundary even lower than $12^{\circ}$ if a small sea-ice albedo of 0.45 is applied (Pierrehumbert et al., 2011). Similarly high sea-ice fractions (critical sea-ice latitudes between $5-15^{\circ}$ ) were also found by Abbot et al. (2011) for stable so-called Jormungand states with the CAM atmosphere model coupled to an ocean mixed layer that neglects ocean 
heat transport and sea-ice dynamics and uses a large difference between bare sea-ice albedo (0.45) and snow-covered sea-ice albedo (0.79). However, other simulations have indicated that such narrow waterbelt states become unstable when sea-ice dynamics are taken into account (Lewis et al., 2007; Voigt and Abbot, 2012). Nevertheless, the spread of results among different studies due to specific model properties and sea-ice settings is significant and also simulations with complex models support the possibility of stable glaciation up to $10^{\circ}$ in the Neoproterozoic (Yang et al., 2012a).

Note that the possibility of such stable states with a narrow belt of open water in the Neoproterozoic does not necessarily imply the existence of such states during the Archean where the reduction in solar luminosity results in a relative decrease of energy input around the equator, even when compensated by enhanced levels of greenhouse gases. Furthermore, our model uses both a low value of the bare sea-ice albedo in agreement with observations of different types of sea ice (as, e.g. reviewed by Warren et al., 2002) and takes sea-ice dynamics into account. Thus, we consider the lack of a stable waterbelt state in our simulations robust. A dedicated study of the sensitivity of our results for the early Archean with respect to sea-ice and snow albedo was presented in Sect. 5.3.

Also, differences in the planetary albedo due to clouds are subject to more principle discussions beyond our model simulations. For example, the vertical resolution of the cloud module or changes in cloud properties which are not taken into account in our model (as, e.g. the droplet size) may have an impact on the radiative forcing. In this context, general constraints for the maximum cloud contribution to Archean warming are provided by Goldblatt and Zahnle (2011) who also review such processes which might strongly modify Archean cloud fractions and which are not represented in our model. For example, the size of cloud particles depends on the abundance of cloud condensation nuclei which are partly biogenic; and it was suggested that their absence in the Archean may have been responsible for significant warming (Rosing et al., 2010).

\section{Future work}

As described in Sect. 2, the model CLIMBER-3 $\alpha$ is a fully coupled atmosphere-ocean model, consisting of an ocean GCM and representing sea-ice dynamics, but with an atmosphere module that applies some parameterizations so that it is computationally more efficient than an atmospheric GCM. Therefore, it was possible to perform the large number of simulations needed for the results presented in this paper.

While we have investigated the robustness of our results with respect to different model parameters and boundary conditions in Sect. 5, it would be desirable to compare our results with future studies using different models. Within the limits of computational feasibility, a comparison with simulations relying on more complex climate models which include a state-of-the-art atmospheric GCM would be valuable. In those models, the atmospheric meridional circulation and the atmosphere's vertical structure are represented in a more fundamental way and individual eddies are resolved. This would allow to explicitly validate our parameterizations under Archean boundary conditions.

\section{Conclusions}

We have modified a 3-D climate model in order to simulate possible climate states of the early Archean that have different $\mathrm{CO}_{2}$ partial pressures: 0.4 bar (critical state, $268 \mathrm{~K}$ global mean SAT), 0.6 bar ( $288 \mathrm{~K}$ state) and 0.8 bar (ice-free, $300 \mathrm{~K}$ global mean SAT). The main model modifications concern the topography, the long-wave radiative transfer scheme, the parameterization of the lapse rate and the prescribed annual means of the atmospheric meridional cell boundaries. These properties and parameterizations are fundamental for the energy balance, including the greenhouse effect of $\mathrm{CO}_{2}$, and for heat redistribution. Key characteristics of the climate states contributing to the global energy balance have been presented. While the Archean solar insolation is well known, other factors such as the continental fraction and distribution involve significant uncertainty or are even unknown. Therefore, we have based our study on one random reference continent distribution, but presented the results of additional simulations in order to estimate the uncertainty due to the topography, thus making use of the computational efficiency of our model. The effect of changes in continent distribution or an increase of the continental fraction from about 1 to $5 \%$ turn out to be minor. As the long-wave radiative properties of $\mathrm{CO}_{2}$-rich atmospheres are still under debate, we have further shown the impact of different parameterizations in this respect, which result in significantly different $\mathrm{CO}_{2}$ partial pressures of the critical states. The critical partial pressure is also influenced by the choice of snow albedo while different settings for the sea-ice albedo appear to be of minor importance in our simulations due to the almost complete snow cover of sea ice. The uncertainty in our knowledge of the early Archean rotation rate leads to a likely range of critical $p \mathrm{CO}_{2}$ between 0.36 and 0.43 bar.

Regarding the overall latitudinal SAT profiles of the simulated climate states, it was found that the one corresponding to the state with $288 \mathrm{~K}$ is quite symmetric and exhibits a larger equator-to-pole difference than in the pre-industrial climate. As the sea-ice albedo feedback plays a significant role in setting this temperature profile and the required $\mathrm{CO}_{2}$ partial pressure, we have presented the sea-ice boundaries corresponding to the different states and found that basically all sea ice is snow-covered, which leads to a high mean surface albedo. The radiative impact of clouds in our simulations is largely due to stratus clouds which in total provide a cooling effect, and the corresponding radiative forcing is smaller 
than today in all three early Archean states due to the lower solar luminosity.

The atmospheric meridional circulation as well as zonal winds are weaker in the early Archean state with $288 \mathrm{~K}$ mean SAT compared to present-day. This contributes to the overall reduction of meridional heat transport found for the early Archean, with the strongest reduction occurring for the warmest (ice-free) early Archean state. The second contribution to it comes from the oceanic heat transport, which is decreased going along with the lack of a deep and far-reaching meridional overturning circulation in the absence of significant continental boundaries. Apart from the shallow winddriven overturning cells, the main oceanic circulation pattern consists of zonal flows.

Furthermore, based on the relation between surface (or planetary) albedo and surface air temperature, we suggest a parameterization of the ice-albedo effect for 1-D radiativeconvective models. An ensemble of 3-D simulations over a broad range of greenhouse gas forcing has been required for providing a suitable parameterization which can be used in future studies with simpler models.

Acknowledgements. We are grateful to David Ferreira for providing electronic data as well as Anthony Bosse, Sylvain Bouillon, Dim Coumou, Alexey Eliseev, Nicolas Flament, Matthias Hofmann, Miguel Morales Maqueda and Stefan Petri for discussions. We acknowledge the World Climate Research Programme's Working Group on Coupled Modelling, which is responsible for CMIP, and we thank the climate modelling groups for producing and making available their model output. We also thank the involved groups/institutions for making available the CALIPSO-GOCCP cloud data. H. Kienert acknowledges support by the Evangelisches Studienwerk Villigst e.V.

Edited by: Y. Godderis

\section{References}

Abbot, D. S., Voigt, A., and Koll, D.: The Jormungand global climate state and implications for Neoproterozoic glaciations, J. Geophys. Res., 116, D18103, doi:10.1029/2011JD015927, 2011.

Bahcall, J. N., Pinsonneault, M. H., and Basu, S.: Solar models: current epoch and time dependences, neutrinos, and helioseismological properties, Astrophys. J., 555, 990-1012, doi:10.1086/321493, 2001.

Belousova, E. A., Kostitsyn, Y. A., Griffin, W. L., Begg, G. C., O'Reilly, S. Y., and Pearson, N. J.: The growth of the continental crust: constraints from zircon Hf-isotope data, Lithos, 119, 457-466, doi:10.1016/j.lithos.2010.07.024, 2010.

Berger, A. L.: Long-term variations of daily insolation and quaternary climatic changes, J. Atmos. Sci., 35, 2362-2367, doi:10.1175/1520-0469(1978)035<2362:LTVODI > 2.0.CO;2, 1978.

Brandt, R. E., Warren, S. G., Worby, A. P., and Grenfell, T. C.: Surface Albedo of the Antarctic Sea Ice Zone, J. Climate, 18, 3606-3622, doi:10.1175/JCLI3489.1, 2005.
Bryan, K. and Lewis, L. J.: A water mass model of the world ocean, J. Geophys. Res., 84, 2503-2517, doi:10.1029/JC084iC05p02503, 1979.

Budyko, M. I.: The effect of solar radiation variations on the climate of the earth, Tellus, 21, 611-619, doi:10.1111/j.21533490.1969.tb00466.x, 1969.

Campbell, I. H.: Constraints on continental growth models from $\mathrm{Nb} / \mathrm{U}$ ratios in the $3.5 \mathrm{Ga}$ Barberton and other $\mathrm{Ar}$ chaean basalt-komatiite suites, Am. J. Sci., 303, 319-351, doi:10.2475/ajs.303.4.319, 2003.

Cesana, G. and Chepfer, H.: How well do climate models simulate cloud vertical structure? A comparison between CALIPSOGOCCP satellite observations and CMIP5 models, Geophys. Res. Lett., 39, L20803, doi:10.1029/2012GL053153, 2012.

Chepfer, H., Bony, S., Winker, D., Cesana, G., Dufresne, J. L., Minnis, P., Stubenrauch, C. J., and Zeng, S.: The GCM-Oriented CALIPSO Cloud Product (CALIPSO-GOCCP), J. Geophys. Res.-Atmos., 115, D00H16, doi:10.1029/2009JD012251, 2010.

Claussen, M., Mysak, L. A., Weaver, A. J., Crucifix, M., Fichefet, T., Loutre, M.-F., Weber, S. L., Alcamo, J., Alexeev, V. A., Berger, A., Calov, R., Ganopolski, A., Goosse, H., Lohmann, G., Lunkeit, F., Mokhov, I. I., Petoukhov, V., Stone, P., and Wang, Z.: Earth system models of intermediate complexity: closing the gap in the spectrum of climate system models, Clim. Dynam., 18, 579-586, doi:10.1007/s00382-001-0200-1, 2002.

Clough, S. A., Shephard, M. W., Mlawer, E. J., Delamere, J. S., Iacono, M. J., Cady-Pereira, K., Boukabara, S., and Brown, P. D.: Atmospheric radiative transfer modeling: a summary of the AER codes, J. Quant. Spectrosc. Ra., 91, 233-244, 2005.

Collins, W. D., Rasch, P. J., Boville, B. A., Hack, J. J., McCaa, J. R., Williamson, D. L., Kiehl, J. T., Briegleb, B., Bitz, C., and Lin, S. J.: Description of the NCAR community atmosphere model (CAM 3.0), Technical Note TN-464+ STR, National Center for Atmospheric Research, Boulder, CO, 2004.

Dhuime, B., Hawkesworth, C. J., Cawood, P. A., and Storey, C. D.: A change in the geodynamics of continental growth 3 billion years ago, Science, 335, 1334-1336, doi:10.1126/science.1216066, 2012.

Eby, M., Weaver, A. J., Alexander, K., Zickfeld, K., Abe-Ouchi, A., Cimatoribus, A. A., Crespin, E., Drijfhout, S. S., Edwards, N. R., Eliseev, A. V., Feulner, G., Fichefet, T., Forest, C. E., Goosse, H., Holden, P. B., Joos, F., Kawamiya, M., Kicklighter, D., Kienert, H., Matsumoto, K., Mokhov, I. I., Monier, E., Olsen, S. M., Pedersen, J. O. P., Perrette, M., Philippon-Berthier, G., Ridgwell, A., Schlosser, A., Schneider von Deimling, T., Shaffer, G., Smith, R. S., Spahni, R., Sokolov, A. P., Steinacher, M., Tachiiri, K., Tokos, K., Yoshimori, M., Zeng, N., and Zhao, F.: Historical and idealized climate model experiments: an intercomparison of Earth system models of intermediate complexity, Clim. Past, 9, 11111140, doi:10.5194/cp-9-1111-2013, 2013.

Enderton, D. and Marshall, J.: Explorations of atmosphereocean-ice climates on an aquaplanet and their meridional energy transports, J. Atmos. Sci., 66, 1593-1611, doi:10.1175/2008JAS2680.1, 2009.

Ferreira, D., Marshall, J., and Campin, J. M.: Localization of deep water formation: role of atmospheric moisture transport and geometrical constraints on ocean circulation, J. Climatol., 23, 14561476, doi:10.1175/2009JCLI3197.1, 2010. 
Feulner, G.: The faint young Sun problem, Rev. Geophys., 50, RG2006, doi:10.1029/2011RG000375, 2012.

Fichefet, T. and Morales Maqueda, M. A.: Sensitivity of a global sea ice model to the treatment of ice thermodynamics and dynamics, J. Geophys. Res.-Oceans, 102, 12609-12646, 1997.

Flament, N.: Secular cooling of the solid Earth, emergence of the continents, and evolution of Earth's external envelopes, Ph.D. thesis, University of Sydney and École Normale Supérieure de Lyon, Lyon, 2009.

Flament, N., Coltice, N., and Rey, P. F.: A case for lateArchaean continental emergence from thermal evolution models and hypsometry, Earth Planet. Sc. Lett., 275, 326-336, doi:10.1016/j.epsl.2008.08.029, 2008.

Forster, P., Ramaswamy, V., Artaxo, P., Berntsen, T., Betts, R., Fahey, D. W., Haywood, J., Lean, J., Lowe, D. C., Myhre, G., Nganga, J., Prinn, R., Raga, G., Schulz, M., and Van Dorland, R.: Climate Change 2007: The Physical Science Basis. Contribution of Working Group I to the Fourth Assessment Report of the Intergovernmental Panel on Climate Change, in: chap. Changes in Atmospheric Constituents and in Radiative Forcing, Cambridge University Press, Cambridge, UK and New York, NY, USA, 2007.

Gent, P. R. and McWilliams, J. C.: Isopycnal mixing in ocean circulation models, J. Phys. Oceanogr., 20, 150-155, doi:10.1175/1520-0485(1990)020<0150:IMIOCM > 2.0.CO;2, 1990.

Goldblatt, C. and Zahnle, K. J.: Clouds and the Faint Young Sun Paradox, Clim. Past, 7, 203-220, doi:10.5194/cp-7-203-2011, 2011.

Goldblatt, C., Claire, M. W., Lenton, T. M., Matthews, A. J., Watson, A. J., and Zahnle, K. J.: Nitrogen-enhanced greenhouse warming on early Earth, Nat. Geosci., 2, 891-896, doi:10.1038/ngeo692, 2009.

Gregory, J. M., Ingram, W. J., Palmer, M. A., Jones, G. S., Stott, P. A., Thorpe, R. B., Lowe, J. A., Johns, T. C., and Williams, K. D.: A new method for diagnosing radiative forcing and climate sensitivity, Geophys. Res. Lett., 31, L03205, doi:10.1029/2003GL018747, 2004.

Gregory, J. M., Dixon, K. W., Stouffer, R. J., Weaver, A. J., Driesschaert, E., Eby, M., Fichefet, T., Hasumi, H., Hu, A., Jungclaus, J. H., Kamenkovich, I. V., Levermann, A., Montoya, M., Murakami, S., Nawrath, S., Oka, A., Sokolov, A. P., and Thorpe, R. B.: A model intercomparison of changes in the Atlantic thermohaline circulation in response to increasing atmospheric $\mathrm{CO}_{2}$ concentration, Geophys. Res. Lett., 32, L12703, doi:10.1029/2005GL023209, 2005.

Halevy, I., Pierrehumbert, R. T., and Schrag, D. P.: Radiative transfer in $\mathrm{CO}_{2}$-rich paleoatmospheres, J. Geophys. Res., 114, D18112, doi:10.1029/2009JD011915, 2009.

Hansen, J., Sato, M., Ruedy, R., Nazarenko, L., Lacis, A., Schmidt, G. A., Russell, G., Aleinov, I., Bauer, M., Bauer, S., Bell, N., Cairns, B., Canuto, V., Chandler, M., Cheng, Y., Del Genio, A., Faluvegi, G., Fleming, E., Friend, A., Hall, T., Jackman, C., Kelley, M., Kiang, N., Koch, D., Lean, J., Lerner, J., Lo, K., Menon, S., Miller, R., Minnis, P., Novakov, T., Oinas, V., Perlwitz, J., Perlwitz, J., Rind, D., Romanou, A., Shindell, D., Stone, P., Sun, S., Tausnev, N., Thresher, D., Wielicki, B., Wong, T., Yao, M., and Zhang, S.: Efficacy of climate forcings, J. Geophys. Res.Atmos., 110, D18104, doi:10.1029/2005JD005776, 2005.
Held, I. M. and Hou, A. Y.: Nonlinear axially symmetric circulations in a nearly inviscid atmosphere, J. Atmos. Sci., 37, 515$533,1980$.

Hofmann, M. and Morales Maqueda, M. A.: Performance of a second-order moments advection scheme in an ocean general circulation model, J. Geophys. Res.-Oceans, 111, C05006, doi:10.1029/2005JC003279, 2006.

Hurley, P. M. and Rand, J. R.: Pre-drift continental nuclei, Science, 164, 1229-1242, doi:10.1126/science.164.3885.1229, 1969.

Hyde, W. T., Crowley, T. J., Baum, S. K., and Peltier, W. R.: Neoproterozoic "snowball Earth" simulations with a coupled climate/ice-sheet model, Nature, 405, 425-429, doi:10.1038/35013005, 2000.

Jansen, E., Overpeck, J., Briffa, K. R., Duplessy, J.-C., Joos, F., Masson-Delmotte, V., Olago, D., Otto-Bliesner, B., Peltier, W. R., Rahmstorf, S., Ramesh, R., Raynaud, D., Rind, D., Solomina, O., Villalba, R., and Zhang, D.: Climate Change 2007: The Physical Science Basis. Contribution of Working Group I to the Fourth Assessment Report of the Intergovernmental Panel on Climate Change, chap. Palaeoclimate, Cambridge University Press, Cambridge, UK and New York, NY, USA, 2007.

Jenkins, G. S.: A general circulation model study of the effects of faster rotation rate, enhanced $\mathrm{CO}_{2}$ concentration, and reduced solar forcing: implications for the faint young sun paradox, J. Geophys. Res., 98, 20803-20811, doi:10.1029/93JD02056, 1993a.

Jenkins, G. S.: The effects of reduced land fraction and solar forcing on the general circulation: results from the NCAR CCM, Global Planet. Change, 7, 321-333, doi:10.1016/0921-8181(93)900048, 1993b.

Jenkins, G. S.: Early Earth's climate: Cloud feedback from reduced land fraction and ozone concentrations, Geophys. Res. Lett., 22, 1513-1516, doi:10.1029/95GL00818, 1995.

Jenkins, G. S.: A sensitivity study of changes in Earth's rotation rate with an atmospheric general circulation model, Global Planet. Change, 11, 141-154, doi:10.1016/0921-8181(95)00050X, 1996.

Jenkins, G. S., Marshall, H. G., and Kuhn, W. R.: Precambrian climate: The effects of land area and Earth's rotation rate, J. Geophys. Res., 98, 8785-8791, doi10.1029/93JD00033, 1993.

Kasting, J. F.: Early Earth: faint young Sun redux, Nature, 464, 687689, doi:10.1038/464687a, 2010.

Kasting, J. F., Pollack, J. B., and Crisp, D.: Effects of high $\mathrm{CO}_{2}$ levels on surface temperature and atmospheric oxidation state of the early earth, J. Atmos. Chem., 1, 403-428, doi:10.1007/BF00053803, 1984.

Kiehl, J. T. and Dickinson, R. E.: A study of the radiative effects of enhanced atmospheric $\mathrm{CO}_{2}$ and $\mathrm{CH}_{4}$ on early Earth surface temperatures, J. Geophys. Res., 92, 2991-2998, doi:10.1029/JD092iD03p02991, 1987.

Kienert, H., Feulner, G., and Petoukhov, V.: Faint young Sun problem more severe due to ice-albedo feedback and higher rotation rate of the early Earth, Geophys. Res. Lett., 39, L23710, doi:10.1029/2012GL054381, 2012.

Kirschvink, J. L.: Late proterozoic low-latitude global glaciation: the snowballl earth, in: The Proterozoic Biosphere: A Multidisciplinary Study, edited by: Schopf, J. W. and Klein, C., Cambridge University Press, Cambridge, 51-52, 1992. 
Kröner, A.: Evolution of the archean continental crust, Annu. Rev. Earth Planet. Sci., 13, 49-74, doi:10.1146/annurev.ea.13.050185.000405, 1985.

Labrosse, S. and Jaupart, C.: Thermal evolution of the Earth: secular changes and fluctuations of plate characteristics, Earth Planet. Sc. Lett., 260, 465-481, doi:10.1016/j.eps1.2007.05.046, 2007.

Large, W. G., McWilliams, J. C., and Doney, S. C.: Oceanic vertical mixing: a review and a model with a nonlocal boundary layer parameterization, Rev. Geophys., 32, 363-403, doi:10.1029/94RG01872, 1994.

Lewis, J. P., Weaver, A. J., and Eby, M.: Snowball versus slushball Earth: dynamic versus nondynamic sea ice?, J. Geophys. Res.Oceans, 112, doi:10.1029/2006JC004037, 2007.

Lowe, D. R.: Archean sedimentation, Annu. Rev. Earth Planet. Sci., 8, 145-167, doi:10.1146/annurev.ea.08.050180.001045, 1980.

Marshall, J., Ferreira, D., Campin, J.-M., and Enderton, D.: Mean climate and variability of the atmosphere and ocean on an aquaplanet, J. Atmos. Sci., 64, 4270-4286, doi:10.1175/2007JAS2226.1, 2007.

Meadows, V. S. and Crisp, D.: Ground-based near-infrared observations of the Venus nightside: the thermal structure and water abundance near the surface, J. Geophys. Res., 101, 4595-4622, 1996.

Montoya, M., Griesel, A., Levermann, A., Mignot, J., Hofmann, M., Ganopolski, A., and Rahmstorf, S.: The earth system model of intermediate complexity CLIMBER-3 $\alpha$, Part 1 : description and performance for present-day conditions, Clim. Dynam., 25, 237263, doi:10.1007/s00382-005-0044-1, 2005.

Navarra, A. and Boccaletti, G.: Numerical general circulation experiments of sensitivity to Earth rotation rate, Clim. Dynam., 19, 467-483, doi:10.1007/s00382-002-0238-8, 2002.

Pacanowski, R. C. and Griffies, S. M.: The MOM-3 manual, Tech. Rep. 4, NOAA/Geophyical Fluid Dynamics Laboratory, Princeton, NJ, USA, 1999.

Petoukhov, V., Ganopolski, A., Brovkin, V., Claussen, M., Eliseev, A., Kubatzki, C., and Rahmstorf, S.: CLIMBER-2: a climate system model of intermediate complexity, Part I: model description and performance for present climate, Clim. Dynam., 16, 1-17, 2000.

Petoukhov, V., Ganopolski, A., and Claussen, M.: POTSDAM - a set of atmosphere statistical-dynamical models: theoretical background, Tech. Rep. 81, Potsdam Institute for Climate Impact Research, Potsdam, 2003.

Pierrehumbert, R. T.: Principles of Planetary Climate, Cambridge University Press, Cambridge, 2010.

Pierrehumbert, R. T., Abbot, D. S., Voigt, A., and Koll, D.: Climate of the Neoproterozoic, in: Annual Review of Earth and Planetary Sciences, Vol. 39, edited by: Jeanloz, R. and Freeman, K. H., Annual Reviews, Palo Alto, 417-460, 2011.

Plattner, G.-K., Knutti, R., Joos, F., Stocker, T. F., von Bloh, W., Brovkin, V., Cameron, D., Driesschaert, E., Dutkiewicz, S., Eby, M., Edwards, N. R., Fichefet, T., Hargreaves, J. C., Jones, C. D., Loutre, M. F., Matthews, H. D., Mouchet, A., Müller, S. A., Nawrath, S., Price, A., Sokolov, A., Strassmann, K. M., and Weaver, A. J.: Long-term climate commitments projected with climate carbon cycle models, J. Climatol., 21, 2721, doi:10.1175/2007JCLI1905.1, 2008.
Redi, M. H.: Oceanic isopycnal mixing by coordinate rotation, J. Phys. Oceanogr., 12, 1154-1158, doi:10.1175/15200485(1982)012<1154:OIMBCR > 2.0.CO;2, 1982.

Rey, P. F. and Coltice, N.: Neoarchean lithospheric strengthening and the coupling of Earth's geochemical reservoirs, Geology, 36, 635-638, 2008.

Rosing, M. T., Bird, D. K., Sleep, N. H., and Bjerrum, C. J.: No climate paradox under the faint early Sun, Nature, 464, 744-747, doi:10.1038/nature08955, 2010.

Sagan, C. and Mullen, G.: Earth and Mars: Evolution of atmospheres and surface temperatures, Science, 177, 52-56, doi:10.1126/science.177.4043.52, 1972.

Schneider, T.: The General Circulation of the Atmosphere, Ann. Rev. Earth Pl. Sc., 34, 655-688, doi:10.1146/annurev.earth.34.031405.125144, 2006.

Segura, A., Meadows, V. S., Kasting, J. F., Crisp, D., and Cohen, M.: Abiotic formation of $\mathrm{O}_{2}$ and $\mathrm{O}_{3}$ in high- $\mathrm{CO}_{2}$ terrestrial atmospheres, Astron. Astrophys., 472, 665-679, doi:10.1051/00046361:20066663, 2007.

Shine, K.P. and Henderson-Sellers, A.: The sensitivity of a thermodynamic sea ice model to changes in surface albedo parameterization, J. Geophys. Res., 90, 2243-2250, doi:10.1029/JD090iD01p02243, 1985.

Showman, A. P., Cho, J. Y.-K., and Menou, K.: Atmospheric Circulation of Exoplanets, in: Exoplanets, edited by: Seager, S., University of Arizona Press, Tucson, AZ, USA, 471-516, 2011.

Smith, R. S., Dubois, C., and Marotzke, J.: Global climate and ocean circulation on an aquaplanet ocean-atmosphere general circulation model, J. Climatol., 19, 4719-4737, 2006.

Stephens, G. L.: Cloud feedbacks in the climate system: a critical review, J. Climatol., 18, 237-273, doi:10.1175/JCLI-3243.1, 2005.

Stone, P. H.: Constraints on dynamical transports of energy on a spherical planet, Dynam. Atmos. Ocean, 2, 123-139, doi:10.1016/0377-0265(78)90006-4, 1978.

Stone, P. H. and Carlson, J. H.: Atmospheric lapse rate regimes and their parameterization, J. Atmos. Sci., 36, 415-423, 1979.

Stouffer, R. J., Yin, J., Gregory, J. M., Dixon, K. W., Spelman, M. J., Hurlin, W., Weaver, A. J., Eby, M., Flato, G. M., Hasumi, H., Hu, A., Jungclaus, J. H., Kamenkovich, I. V., Levermann, A., Montoya, M., Murakami, S., Nawrath, S., Oka, A., Peltier, W. R., Robitaille, D. Y., Sokolov, A., Vettoretti, G., and Weber, S. L.: Investigating the causes of the response of the thermohaline circulation to past and future climate changes, J. Climatol., 19, 1365-1387, doi:10.1175/JCLI3689.1, 2006.

Taylor, K. E., Stouffer, R. J., and Meehl, G. A.: An overview of CMIP5 and the experiment design, B. Am. Meteorol. Soc., 93, 485-498, doi:10.1175/BAMS-D-11-00094.1, 2012.

Taylor, S. R. and McLennan, S. M.: The Continental Crust: Its Composition and Evolution, Blackwell, Palo Alto, CA, 1985.

Tsvetsinskaya, E. A., Schaaf, C. B., Gao, F., Strahler, A. H., Dickinson, R. E., Zeng, X., and Lucht, W.: Relating MODISderived surface albedo to soils and rock types over Northern Africa and the Arabian peninsula, Geophys. Res. Lett., 29, 1353, doi:10.1029/2001GL014096, 2002.

Voigt, A. and Abbot, D. S.: Sea-ice dynamics strongly promote Snowball Earth initiation and destabilize tropical sea-ice margins, Clim. Past, 8, 2079-2092, doi:10.5194/cp-8-2079-2012, 2012. 
Voigt, A. and Marotzke, J.: The transition from the present-day climate to a modern Snowball Earth, Clim. Dynam., 35, 887-905, doi:10.1007/s00382-009-0633-5, 2010.

Voigt, A., Abbot, D. S., Pierrehumbert, R. T., and Marotzke, J.: Initiation of a Marinoan Snowball Earth in a state-of-the-art atmosphere-ocean general circulation model, Clim. Past, 7, 249263, doi:10.5194/cp-7-249-2011, 2011.

von Paris, P., Rauer, H., Lee Grenfell, J., Patzer, B., Hedelt, P., Stracke, B., Trautmann, T., and Schreier, F.: Warming the early earth $-\mathrm{CO}_{2}$ reconsidered, Planet. Space Sci., 56, 1244-1259, doi:10.1016/j.pss.2008.04.008, 2008.

Walker, J. C. G.: Climatic factors on the Archean Earth, Palaeogeogr. Palaeocl., 40, 1-11, doi:10.1016/0031-0182(82)90082-7, 1982.

Wang, W. C. and Stone, P. H.: Effect of ice-albedo feedback on global sensitivity in a one-dimensional radiative-convective climate model, J. Atmos. Sci., 37, 545-552, doi:10.1175/15200469(1980)037<0545:EOIAFO > 2.0.CO;2, 1980.

Warren, S. G., Brandt, R. E., Grenfell, T. C., and McKay, C. P.: Snowball Earth: ice thickness on the tropical ocean, J. Geophys. Res.-Oceans, 107, 3167, doi:10.1029/2001JC001123, 2002.

Williams, G. E.: Geological constraints on the Precambrian history of Earth's rotation and the Moon's orbit, Rev. Geophys., 38, 3760, doi:10.1029/1999RG900016, 2000.
Williams, G. P.: The dynamical range of global circulations - I, Clim. Dynam., 2, 205-260, doi:10.1007/BF01371320, 1988.

Wordsworth, R., Forget, F., and Eymet, V.: Infrared collisioninduced and far-line absorption in dense $\mathrm{CO}_{2}$ atmospheres, Icarus, 210, 992-997, doi:10.1016/j.icarus.2010.06.010, 2010.

Yang, J., Peltier, W. R., and Hu, Y.: The initiation of modern "Soft Snowball" and "Hard Snowball" climates in CCSM3, Part I: the influences of solar luminosity, $\mathrm{CO}_{2}$ concentration, and the sea ice/snow albedo parameterization, J. Climatol., 25, 2711-2736, doi:10.1175/JCLI-D-11-00189.1, 2012a.

Yang, J., Peltier, W. R., and Hu, Y.: The initiation of modern "Soft Snowball" and "Hard Snowball" climates in CCSM3, Part II: climate dynamic feedbacks, J. Climatol., 25, 2737-2754, doi:10.1175/JCLI-D-11-00190.1, 2012b.

Zahnle, K. and Walker, J. C. G.: A constant daylength during the precambrian era?, Precambrian Res., 37, 95-105, doi:10.1016/0301-9268(87)90073-8, 1987.

Zilitinkevich, S. S.: On the computation of the basic parameters of the interaction between the atmosphere and the ocean, Tellus, 21, 17-24, doi:10.1111/j.2153-3490.1969.tb00414.x, 1969.

Zilitinkevich, S. S.: Dynamics of the Atmospheric Boundary Layer, Gidrometeoizdat, Leningrad, 1970. 